$$
\begin{aligned}
& \text { FE44-93R410615 } \\
& \text { DOE/RY/10615--TI }
\end{aligned}
$$

Project No. A-9715

RECEIVED

NOV O 91998

OS TI

\title{
Demonstration of Automated Dyebath Reuse in Carpet Manufacturing
}

A project conducted in conjunction with the

Pollution Prevention Assistance Division

Georgia Department of Natural Resources

7 Martin Luther King, Jr. Drive S.W., Suite 450

Atlanta, GA 30334-9004

Under a U.S. Department of Energy Program in

National Industrial Competitiveness through

Energy, Environment, and Economics

$\left(\mathrm{NICE}^{3}\right)$

James L. Clark, Ph.D., P.E.

Project Director

Georgia Institute of Technology

Atlanta, Georgia 30332

November 1997

DISTRIBUTION OF THIS DOCLMENT IS UNHMTED
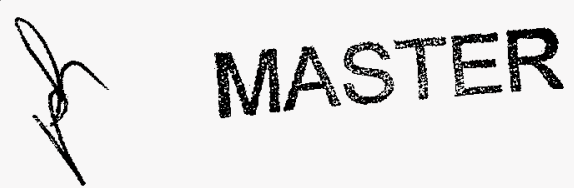


\section{DISCLAIMER}

This report was prepared as an account of work sponsored by an agency of the United States Government. Neither the United States Government nor any agency thereof, nor any of their employees, makes any warranty, express or implied, or assumes any legal liability or responsibility for the accuracy, completeness, or usefulness of any information, apparatus, product, or process disclosed, or represents that its use would not infringe privately owned rights. Reference herein to any specific commercial product, process, or service by trade name, trademark, manufacturer, or otherwise does not necessarily constitute or imply its endorsement, recommendation, or favoring by the United States Government or any agency thereof. The views and opinions of authors expressed herein do not necessarily state or reflect those of the United States Government or any agency thereof. 


\section{DISCLAIMER}

Portions of this document may be illegible in electronic image products. Images are produced from the best available original document. 


\section{A Note from the Project Director}

Although this report is issued by the Project Director at the Georgia Institute of Technology, it presents accomplishments attained through a cooperative effort of federal and state government agencies, a state university, and private industry. Team members in this effort and their organizations are listed below. The contributions from each are sincerely appreciated. In such a diverse project, it is likely that a key participant is overlooked in compiling this list, and apologies are offered in advance.

The U.S. Department of Energy

Eric K. Hass

Timothy A. Eastling

Pollution Prevention Assistance Division of the Georgia Department of Natural Resources

G. Robert Kerr

Gregory D. Andrews

Georgia Research Alliance

William J. Todd

C. Michael Cassidy

Mary G. (Meg) Brown

Shaw Industries

Dennis Jones

J. David Morgan

George Cavanaugh

William Patterson

David Persson

Dirk Green

Gerald Beavers

Jeff Parrott

Dalton Utilities

Don Cope

Georgia Tech Research Institute

James L. Clark

Wiley D. Holcombe

Richard A. Carey

Georgia Tech School of Textile and Fiber Engineering

Wayne C. Tincher

Fred L. Cook

Georgia Tech Graduate Students

Elizabeth W. White

Shiqi Li

Matthew C. Marston

Michael W. Ellis

Stephen J. Alsum

Celena L. Evans 


\section{Contents}

$\underline{\text { Section }}$

Title

Page

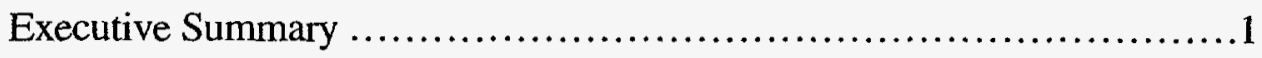

I. Project Justification, Objectives, and Challenges ......................2

A. Conventional Dyeing Process ....................................

B. Opportunities and Challenges...................................

II. Development of a Modified Dyeing Process and System .................7

A. Process Development ...........................................

B. Equipment Modification........................................

III. The Prototype System for Automated Dyebath Analysis................ 12

IV. The Demonstrations of Automated Dyebath Reuse ...................... 14

A. Non-Automated Dyebath Reuse Trial............................... 14

B. Automated Dyebath Reuse Trial, Part I........................... 15

C. Automated Dyebath Reuse Trial, Part II............................ 16

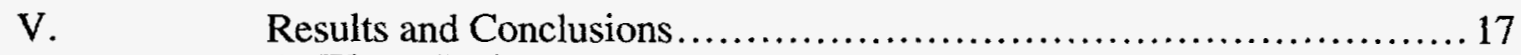

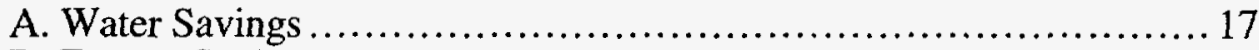

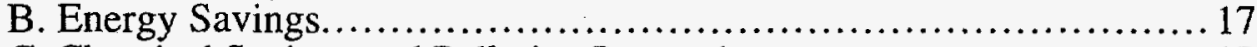

C. Chemical Savings and Pollution Prevention ........................ 17

D. Direct Economic Benefits ............................................. 18

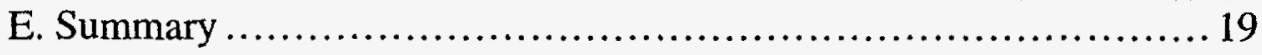

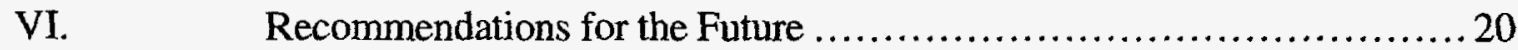

A. Technology Commercialization and Improvement ..................20

B. Automated Dyebath Reuse in Other Textile Applications...............20

C. Use of Automated Analysis for Other Process Improvements...........21

D. Additional BOD/COD Reduction Opportunity ......................21

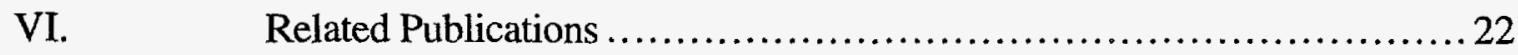

Appendices:

A. The Dye Chemistry Systems Studied and the Preliminary Dyeing Trials............ 23

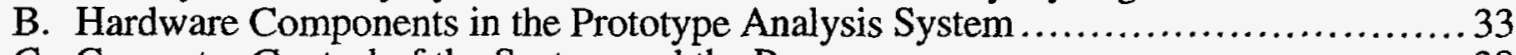

C. Computer Control of the System and the Process ................................ 38

D. Absorbance Measurement and Calculation of Dye Concentrations................... 40

E. Calibration and Validation of the Analysis System............................... 42

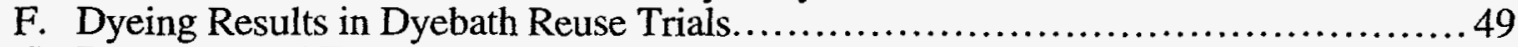

G. Demonstrated Energy, Environmental, and Economic Savings ................... 52 


\section{Figures}

Figure

Title

Page

Carpet Dyebeck in Production....................................... 3

Schematic Diagram of Carpet Dyebeck.................................... 3

Standard Dyeing Process .......................................... 4

Modified Dyeing Process .......................................... 9

Modified Beck with Holding Tank .................................. 10

The Test Beck, Holding Tank, and Analysis System ................... 11

Components of the Automated Analysis System.......................... 12

Analysis System and Enclosures..................................... 13

Dye Exhaustion for Various Process Starting Temperatures

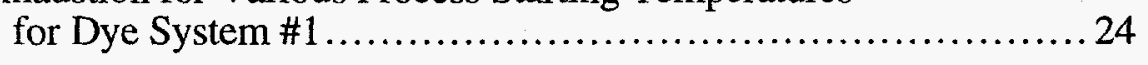

Dyebath Concentration vs. Time for Dye System \#2 …............. 26

Dye Exhaustion for Blue Dye from Dye System \#1 ................... 30

Dye Exhaustion for Red Dye from Dye System \#2 ..................... 30

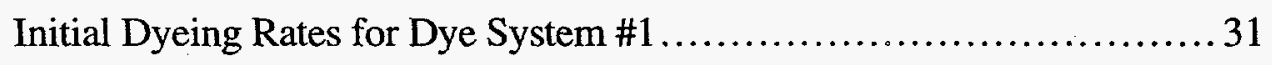

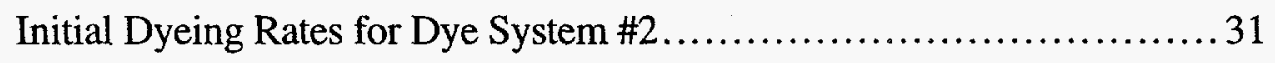

Sample Reservoir .............................................. 32

Spectral Output of Light Source....................................... 34

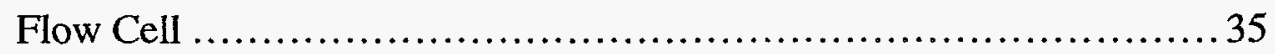

Flow Cell Holder ....................................................... 36 


\section{Tables}

Table

Title

Page

1 Summary of Cost Savings through Automated Dyebath Reuse 18

Hot-Drop Trial Results .23

Hot-Start/Hot-Drop Trial Results for Dye System \#1 .................... 23

Hot-Start/Hot-Drop Trial Results for Dye System \#2 ................... 25

Standard Background Formulas for Nylon 6 and 6,6 Carpets.

Nylon 6,6 Calibration for Non-Automated Dyebath Reuse Trial and Automated Dyebath Reuse Trial, Part I .

Nylon 6 Calibration for Non-Automated Dyebath Reuse Trial and Automated Dyebath Reuse Trial, Part I

Nylon 6 Validation Data for Non-Automated Dyebath Reuse Trial

Nylon 6 Validation Data for Automated Dyebath Reuse Trial, Part I

Nylon 6,6 Calibration for Automated Dyebath Reuse Trial, Part II

Nylon 6 Calibration for Automated Dyebath Reuse Trial, Part II .45

Analysis Results and Savings for Automated Dyebath Reuse Trial, Part I.... 49

Analysis Results and Savings for Automated Dyebath Reuse Trial, Part II .. 50

Calculation of Demonstrated Reduction in Pollutants Released. 52

Calculation of Demonstrated Cost Reduction 


\section{Executive Summary}

This report documents a project conducted under a program of National Industrial Competitiveness through Energy, Environment, and Economics (NICE ${ }^{3}$ ). The program has the objective of developing and demonstrating industrial processes which simultaneously conserve energy and reduce environmental pollution in an economically attractive manner. This project addressed textile dyeing, specifically batch dyeing of nylon carpets with acid dyes, and focused on providing a technically and financially attractive solution which does not impose burdens on the user industry, such as requirements for additional labor or expertise at the production facility.

The batch dyeing of carpet is an inherently wasteful process. After each dye cycle, all of the water, energy, and residual chemicals used to dye the carpets are dumped to the drain. Reuse of the spent dyebaths is a proven technique for reducing consumption of water, chemicals, and energy. However, implementation of reuse on a plant-wide or industry-wide scale is impeded by the human involvement required.

Spent dyebaths must be sampled, analyzed, and reconstituted prior to reuse. This requires skilled labor and expertise which have not been available in the dyehouses, while the time required for these activities and the risk of human errors have placed the process at a disadvantage. For these reasons, dyebath reuse has not (to this point) achieved commercial acceptance, even though the potential for energy, environmental, and economic benefit was clear. Successful implementation of dyebath reuse requires an automated system which can capture spent dyebaths, accurately analyze samples in real-time, and provide for reconstitution and reuse of the bath without significant human involvement beyond that found in the conventional process.

This NICE ${ }^{3}$ project developed and demonstrated a process for automated dyebath reuse, including a prototype automated analysis system. This required development of a modified dye cycle, incorporating hot-start and hot-termination for two different dye systems, as well as integration of the analysis system with the existing process control and production scheduling systems in the plant. The prototype analysis system was installed on a production beck in a commercial dyehouse, and automated dyebath reuse was demonstrated on carpets of both nylon 6 and nylon 6,6 polymers in a variety of colors. The results of the trials show that the automated analysis system can successfully analyze concentrations of multiple dyes in spent dyebaths without operator assistance and that dyebaths can be reconstituted based on these analyses and reused without compromising the quality of the carpets produced. Economic benefits representing savings in water, energy, chemicals, and waste treatment were shown to be approximately three cents per pound of carpet dyed with a reused bath - a significant savings for a typical dyehouse processing tens of millions of pounds of carpet per year.

This report also describes future activities, including commercialization of the prototype for widespread implementation in the carpet manufacturing industry and several opportunities to develop extensions of the technology to other textile products, fiber types, dye classes, and dyeing equipment.

The $\mathrm{NICE}^{3}$ program has been supported by funds from the Department of Energy and the Environmental Protection Agency, while this project received additional financial support from the Pollution Prevention Assistance Division of the Georgia Department of Natural Resources, the Georgia Research Alliance, Shaw Industries, Dalton Utilities, and the Georgia Institute of Technology. 


\section{Project Justification, Objectives, and Challenges}

The textile industry is a major economic force in the southeastern United States, with the world center of the carpet industry located in the vicinity of Dalton, Georgia. In spite of its great contributions, the industry is also a major consumer of water and energy resources and a major source of chemically-polluted wastewater streams. It has been estimated that 160 pounds of water are required to produce each pound of textile product, with most of the water consumed in dyeing and finishing processes. Dyebaths are typically heated almost to the boiling point, consuming substantial energy which is generally not recovered. The vast majority of the water is discharged to the sewer, along with dissolved and suspended organic and inorganic chemicals. The dyeing process places a significant demand on water resources as well as waste treatment facilities, especially in areas such as Dalton, where carpet manufacturing plants are highly concentrated.

The potential benefits which might be obtained by reusing the dyebaths quickly become evident. Previous projects developed technologies to enable dyebath reuse and demonstrated the energy, environmental, and economic savings. However, the technologies were never developed to a level that found commercial acceptance. In light of the economic importance of the industry to the region, continued efforts were justified to enhance the energy and environmental characteristics of the processes. Further improvements to the manufacturing process have been addressed through research, development, and eventually the $\mathrm{NICE}^{3}$ demonstration of new dyebath reuse technology at a Shaw Industries dyehouse.

Discussion of the impediments to dyebath reuse, the objectives of the demonstration program, and the challenges which it faced requires a basic understanding of the conventional manufacturing processes and equipment.

\section{A. Conventional Dyeing Processes}

Both continuous and batch dyeing processes are common for broadloom carpets. Continuous dyeing offers cost advantages and greater ease in obtaining uniform color over a large production lot size. In contrast, batch dyeing is now used predominantly for heavy-weight, high-end carpets which cannot be dyed as well with the continuous processes. Batch processes also offer the advantage of production flexibility due to the small lot size.

Batch dyeing of nylon carpet is performed in a process vessel known as a beck. Figure 1 shows a production beck capable of dyeing up to 2,000 pounds of carpet in a load. A typical recipe for the dyebath consists of 5,000 gallons of water and about 70 pounds of auxiliary chemicals, but only a small quantity of dye, perhaps a total of two pounds. Generally the dye for a batch is a mixture of three components - yellow, red, and blue - with their ratio and total quantity selected to give the desired color for the product. The auxiliary chemicals include wetting agents, $\mathrm{pH}$ control agents, leveling agents, chelating agents, etc., which aid the dyeing process but are not consumed.

The schematic diagram of a carpet beck is shown in Figure 2. This figure shows the vessel filled with dyebath and the carpet loaded and sewn in a loop about a rotating reel which provides agitation. Heating is provided by direct injection of steam (with a baffle to protect the carpet from the piping and from direct contact with the steam), while a pump and circulation loop provide mixing to maintain uniformity of temperature and dye distribution. The water, dyes, and auxiliary chemicals are introduced at the suction side of the circulation pump. 


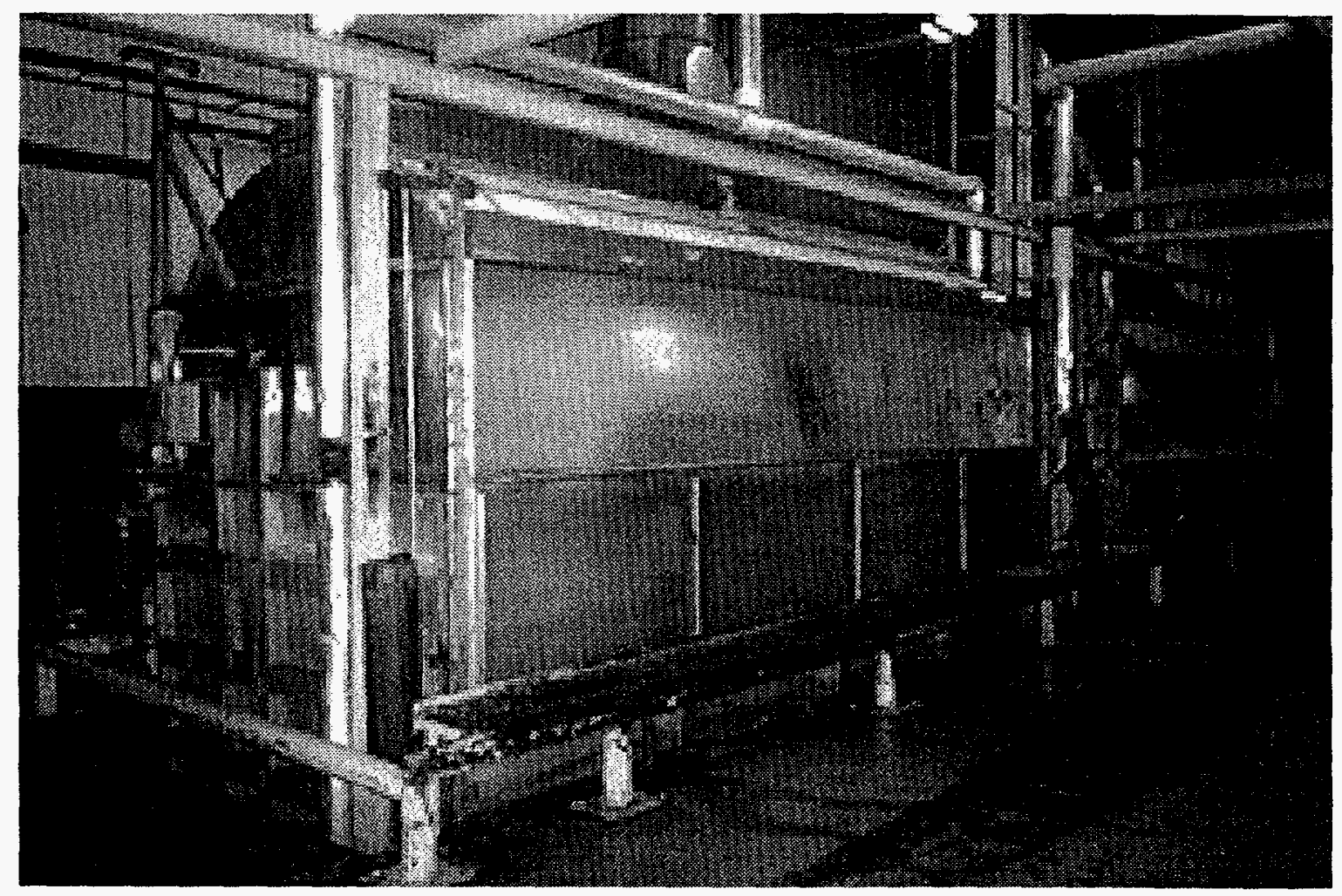

Figure 1. Carpet Dyebeck in Production

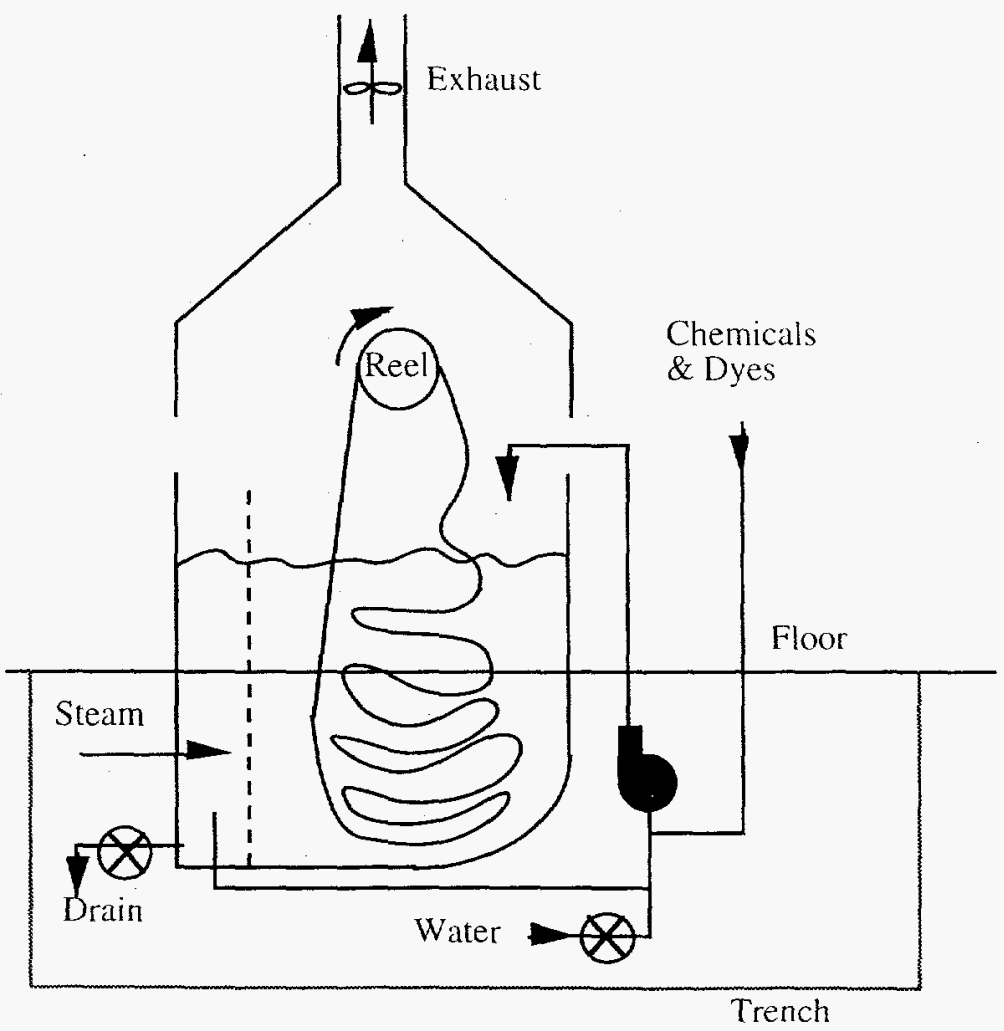

Figure 2. Schematic Diagram of Carpet Dyebeck 
The dyeing process begins with the carpet being rolled onto the reel and the beck filled with water. The carpet is then unwound into the beck and the ends sewn together around the reel. As the reel is rotated and the water circulated, the auxiliary chemicals are added to the bath, followed by the dyes.

The bath is heated at a rate of approximately $2-3 \mathrm{~F}$ per minute from the water supply temperature (year-round average of $\sim 60 \mathrm{~F}$ ) to a temperature of approximately 200 to $208 \mathrm{~F}$, depending on the product. As the temperature of the bath is increased, the dyes adsorb onto the surface of the carpet fiber and diffuse into the amorphous regions of the fiber. The bath is held at the specified temperature for approximately 30 to 70 minutes, again depending on the product, while the carpet is being tumbled and the bath circulated. This allows time for dye migration to ensure a level dyeing (uniform color). After the hold time, the heating stops, and a small patch of the carpet is tested to establish that the carpet is the proper shade.

If the carpet is on shade, the carpet and bath are cooled by dilution with cold water. The drain valve and the water fill valve are alternately opened and closed until the temperature has reached $105 \mathrm{~F}$, the maximum acceptable temperature for personnel to handle the carpet. After the bath is cooled, the carpet is pulled from the beck and transported to the dryer. The bath is then discharged to the drain. It takes approximately 6,000 gallons of diluting water to cool one beck load $(\sim 120 \%$ of the original bath volume). The temperature vs. time and water level vs. time profiles for this process are illustrated in Figure 3. Depending on the product to be dyed in the next load, the beck may or may not be cleaned while it is empty.

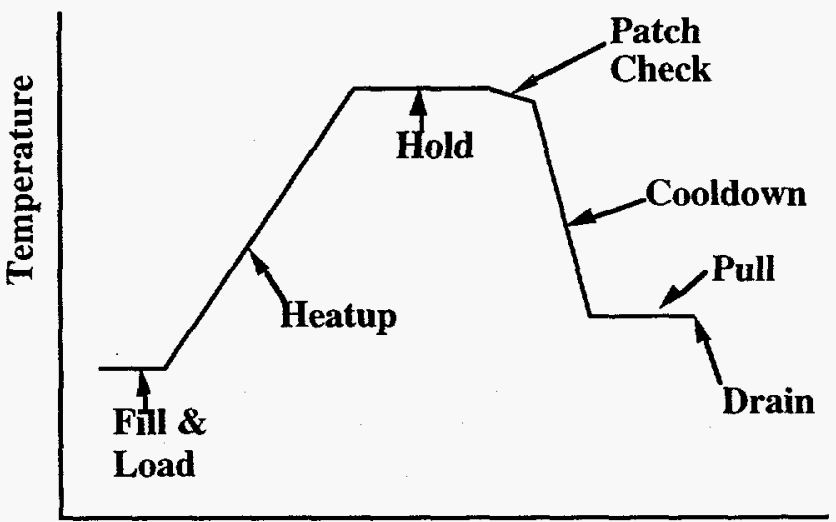

Time

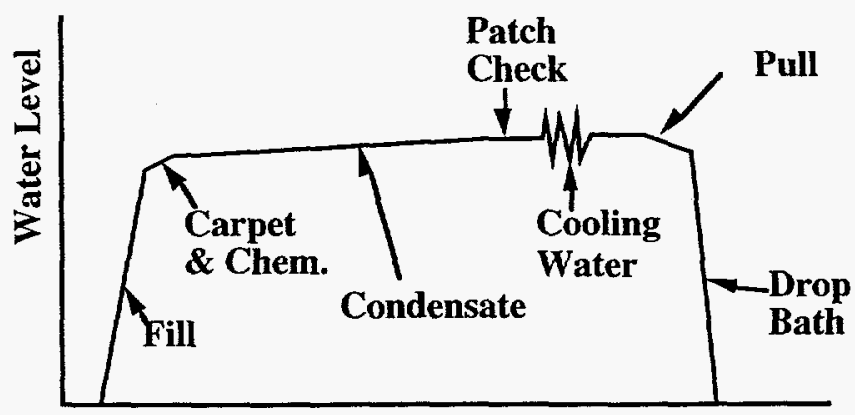

Time

Figure 3. Standard Dyeing Process 
If the patch check shows that the carpet is not on shade, the proper adjustments are estimated, and make-up dyes are prepared and added to the bath. The bath is then reheated to the hold temperature and held again approximately half as long as before, after which another patch check is conducted. This shade adjustment process is referred to as an "add" to the dyeing. This cycle is repeated until a suitable dyeing is achieved. Then the bath is cooled and the carpet removed in the same manner as described earlier.

\section{B. Opportunities and Challenges}

By the time the finished color of the carpet is achieved, the dyebath has undergone several changes. Its temperature is about $200 \mathrm{~F}$, in contrast to the initial temperature of about $60 \mathrm{~F}$. There has been a small amount of dilution due to condensate of the injected steam. Most (but not all) of the dye has been transferred from the bath to the fiber, but the auxiliary chemicals are essentially unchanged.

This spent dyebath, destined for the sewer, represents a significant investment of energy and chemicals which are available for reuse. Dyebath reuse offers an opportunity to reduce the consumption of water resources, to reduce energy consumption in the dyehouse, to conserve/reuse expensive auxiliary chemicals, and to reduce environmental pollution. There is also the potential for production rate increases due to reduced heatup times.

There are several challenges which must be overcome in order to make dyebath reuse possible and attractive to the industry. The first is represented by the small and variable quantity of residual dyes in the spent bath. If these are neglected when a bath is reused, subsequent dyeings will be offshade. It is necessary for the spent bath to be captured, analyzed for the residual quantity of each dye, and reconstituted to the proper concentration of each dye as called for in the recipe for the subsequent batch.

In order to be eligible for dyebath reuse, the subsequent batch must use the same auxiliary chemical recipe and the same component dyes, although it may specify a different shade. In most dyehouses, the majority of the products can be dyed with a combination of just three dyes, typically a yellow, a red, and a blue. Some colors may require a different combination, such as a different yellow dye, or an orange dye instead of yellow. Carpets which use different component dyes in their recipes cannot be dyed in the same reuse sequence because of the dye contamination which would result. Because there are a very small number of combinations used and because the dominant combination generally serves a very large portion of the product line, this limitation should not seriously impact the applicability of dyebath reuse, although attention must be paid to scheduling carpets in a compatible sequence. Similarly, some products use different recipes of auxiliary chemicals, although only two or three combinations are likely to cover almost all of the production.

The second challenge lies in the necessary changes to the dyeing process. Conventional dyeing starts cold with gradual heating, and at the end of the cycle, the bath and carpet are cooled by dilution. For effective capture and reuse of the energy and chemicals, the bath must be recovered hot, without significant dilution, and the subsequent batch must be started hot. Both hot-start and hot-termination of the dyeing process can result in quality defects, and suitable adjustments must be developed and implemented.

The third challenge is automation. Several industrial scale demonstrations of dyebath reuse were conducted in the 1970's and 1980's, demonstrating the technical feasibility and economic advantages. The process did not achieve commercial acceptance because of the human involvement which was required. Even though the savings could justify the added labor, plants were not 
prepared to accept the additional tasks, the additional technical expertise required, nor the risk that human delays or errors in chemical analyses and calculations could adversely impact the production schedule. Thus, commercial acceptance of dyebath reuse requires that the process be automated and not impose significant burden on the production system.

Section II of this report addresses both the development of a suitable dyebath reuse process, eliminating the dilution cooling and avoiding quality problems of hot-start and hot-termination, and the modification of the production system to permit capture and reuse of the dyebath. Section III describes the prototype automated analysis system which was incorporated. 


\section{Development of a Modified Dyeing Process and System}

If dyebath reuse were implemented with the sole objective to maximize recovery of energy and chemicals, then the dyebath would be captured for reuse immediately after the patch check is completed. Since the carpet cannot be pulled from the beck while it is hot, it would be necessary to transfer the entire bath to a holding tank and cool the carpet with a rinse bath. This is called a "hotdrop" or "hot-termination" process. Unfortunately, it can lead to defective carpets.

If the $200 \mathrm{~F}$ dyebath were transferred to the holding tank, the hot carpet would be left folded in the bottom of the beck, with a small fraction of it still looped over the reel. Without the lift provided by the bath, the carpet could not be tumbled by rotating the reel. As the cold rinse water is added to the beck, the carpet would experience rapid cooling, leading to two kinds of quality problems. One is a localized problem, where cold water gives a thermal shock to a fiber tuft, sometimes giving a defect known as "blooming." More notably, as the folded carpet is cooled by the entering water, the yarn passes through a transition temperature, and the fibers are set in their position. This results in permanent creases in the surface fiber, a condition known as a "pile deformation" problem.

Neither blooming nor pile deformation problems can be corrected after they occur, so the carpet cannot be sold as a first-quality product. In the conventional dyeing process, these quality problems are avoided by gradually cooling the carpet while keeping it floating in the bath and tumbling over the reel.

In addition, recovering the dyebath hot means that the subsequent cycle would start at an elevated temperature. While this is desirable from an energy conservation standpoint and even offers a possible production rate improvement, it can lead to additional quality problems. At elevated temperatures, the dyes penetrate the fiber and form their chemical bonds much more readily. As a result, dye tends to bond to the first portion of the carpet it touches, creating non-uniform coloring or unlevel dyeing. In conventional dyeing, the process starts cold, and the continued agitation of the carpet and circulation of the bath contribute to a level dyeing as the temperature increases.

\section{A. Process Development}

In order to develop a suitable dyebath reuse process which avoids dilution of the reusable chemicals and energy and avoids the quality defects associated with hot drops and hot starts, a series of tests were conducted in the Shaw Industries plant during production dyeings. These tests investigated elevated start and termination temperatures and the effects of various preventive measures. These tests are described in Appendix A.

About the same time that a suitable hot-start/hot-drop process had been established, Shaw Industries implemented a corporate decision to convert to a completely different dye chemistry system. The new system behaved quite differently and required significant adjustments even in standard production. When the hot-start/hot-drop process which had been established for the first dye system was tried with the second, serious quality defects resulted, particularly unlevel dyeing. Since there was a corporate commitment to convert all production to the new system, it was necessary to conduct new tests and develop new preventive measures. Developing a suitable hotstart/hot drop process for this second dye system proved to be much more difficult. The two dye systems and their characteristics which affected the reuse process are described in Appendix A. 
The final modified dyeing process, as well as the actual dyebath reuse demonstration, focused on carpets dyed with the second dye system.

Since the critical transition temperature associated with pile deformation is around $195 \mathrm{~F}$ (just below the dyeing temperature), it was suggested that pile deformation problems could be avoided if the folded carpet were below this critical temperature when cold water is added. The cool-down and drop process was modified to cool the bath from $200 \mathrm{~F}$ to $190 \mathrm{~F}$ (to be conservative) by slight dilution before transferring it all to the holding tank, followed by addition of the cold rinse bath to cool the carpet. The bath may be cooled to $190 \mathrm{~F}$ before transferring any of the water to the holding tank, or a significant portion may be transferred (while keeping the carpet floating and agitated), then the remaining bath may be cooled to $190 \mathrm{~F}$ before being transferred. Either procedure works, and there is essentially no difference in the effectiveness of the savings. This measure was shown to eliminate the blooming and pile deformation problems.

Three techniques were introduced to improve the levelness of the dyeing obtained with a hot startup. First, the dyes were fully-diluted in the bath before the bath contacted the carpet. In the conventional process, concentrated dye solutions are added at the circulation pump and fall against the carpet as they enter the beck and before they are distributed throughout the bath. By adding the dyes to reconstitute the bath in the holding tank, they can be fully distributed and less concentrated when they first reach the fiber.

The second technique to improve levelness was to increase the hold time to allow greater migration of the dyes about the carpet. The heatup time is reduced due to the increased startup temperature, and this time savings was fully reinvested in an increased hold time. Thus, opportunities to reduce the total cycle time have not been investigated as a part of this demonstration. It is quite possible that it is not necessary to increase the hold time by the full amount that the heatup is reduced, and future investigations may be able to exploit this facet.

The third technique involves a prerinse bath, the necessity for which is discussed below. The standard recipe of auxiliary chemicals includes a dye leveling agent, and a small amount of this agent was also added to the prerinse bath so that the carpet fibers are fully-treated before they come into contact with the dyes. Tests of these three techniques individually showed significant improvements in dye levelness, and the combination of the three was successful.

In addition to constraints placed on the dyeing process by hot-start and hot-drop of the bath, an additional step had to be added to the modified process. The carpet contains finishes and tints which are added to the fibers during processing. These finishes come off the fiber and go into the bath. They have relatively high optical absorbances which can interfere with the spectrophotometric analysis of the spent dye bath. Therefore, the carpet must first be prerinsed to remove these finishes before the dyeing process begins. The cooling water from the previous batch can be left in the beck after the carpet is removed and used to prerinse the next carpet in order to save water.

The temperature vs. time and water level vs. time profiles of this modified process are shown in Figure 4. For the first carpet in a reuse series, the dyebath is prepared with cold water, so the temperature profile is different from that shown in the figure. Because there is condensate from the injected steam and some cooling water added to the bath, there is more spent dyebath available than can be used in the subsequent batch, and a small amount is dumped to the drain before the cooldown rinse.

While one carpet is cooled and pulled and the next carpet loaded and prerinsed, the spent dyebath is in the holding tank being analyzed and reconstituted to the proper recipe for the next dyeing. The steps in this modified dyeing procedure are listed in Appendix A. 


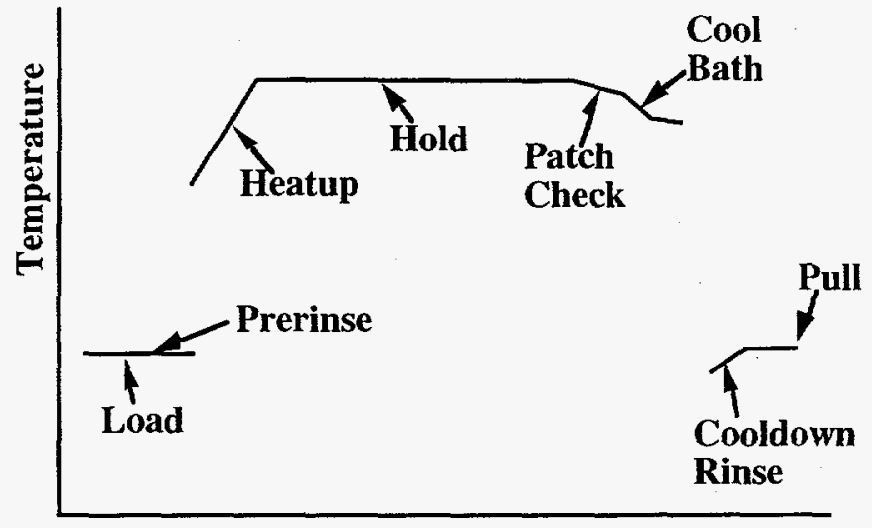

Time

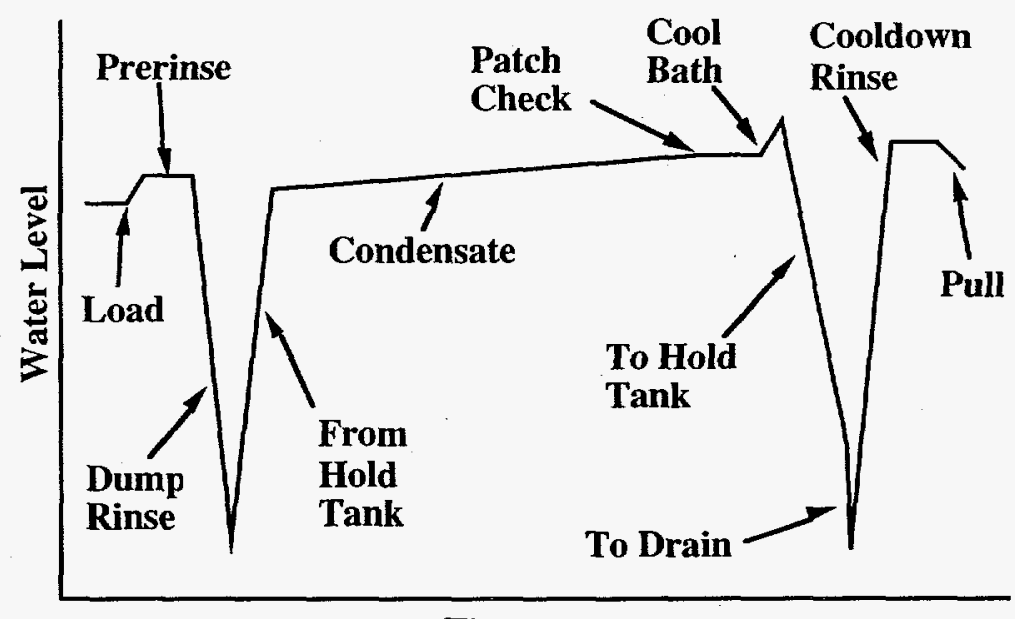

Time

Figure 4. Modified Dyeing Process

\section{B. Equipment Modification}

The production beck for the automated dyebath reuse demonstration was modified to provide the equipment to capture, analyze, and reconstitute the spent dyebath. The modified system is illustrated in Figure 5.

The holding tank used for the demonstration is a cylindrical tank 12 feet tall, 8.5 feet in diameter, with a shallow conical bottom. Hoses and valves have been added to the plumbing so that the existing $800 \mathrm{gpm}$ circulation pump on the beck is used to transfer the bath to the holding tank. The tank is equipped with a $100 \mathrm{gpm}$ recirculation pump which serves several purposes. The pump discharge line gives a convenient point to pull samples of spent dyebath to be sent to the analysis system for testing. After the makeup auxiliary chemicals and dyes are added to the holding tank, the pump provides mixing of the bath in the tank. 


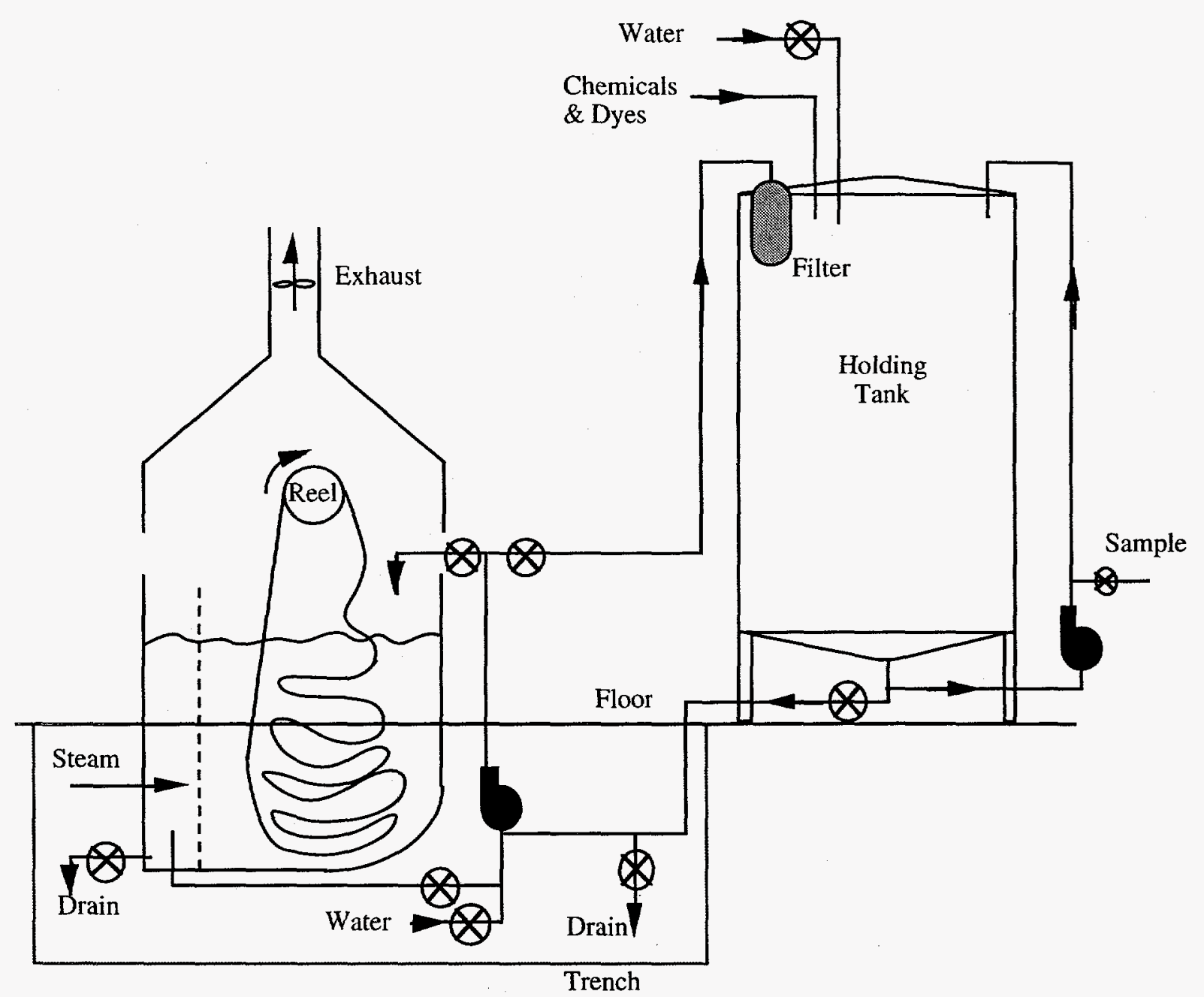

Figure 5. Modified Beck with Holding Tank

The pipeline from the drug room (chemical preparation room) was diverted so that the chemicals and dyes are added at the holding tank and not the beck so that the bath will be fully mixed before it comes in contact with the carpet to prevent levelness problems. The drain line of the holding tank is connected to the suction side of the recirculation pump on the beck for the return transfer of the bath. The return line also contains a valve which permits the holding tank to be drained to the trench if necessary.

A water line is connected to the top of the holding tank. After the bath is transferred to the beck, a small amount of fresh water is added to the holding tank to flush out the remaining dyebath left in the bottom of the tank. The holding tank has a sight glass on the side so that the level of the bath can easily be seen. An adjustable probe has been added in the holding tank to control the fill level so that the appropriate amount of dyebath for reuse in the next batch is transferred to the tank.

Figure 6 is a photograph of the area behind the test beck, showing the holding tank and circulation pump. The prototype analysis system is in the enclosures mounted on the wall on the right. 


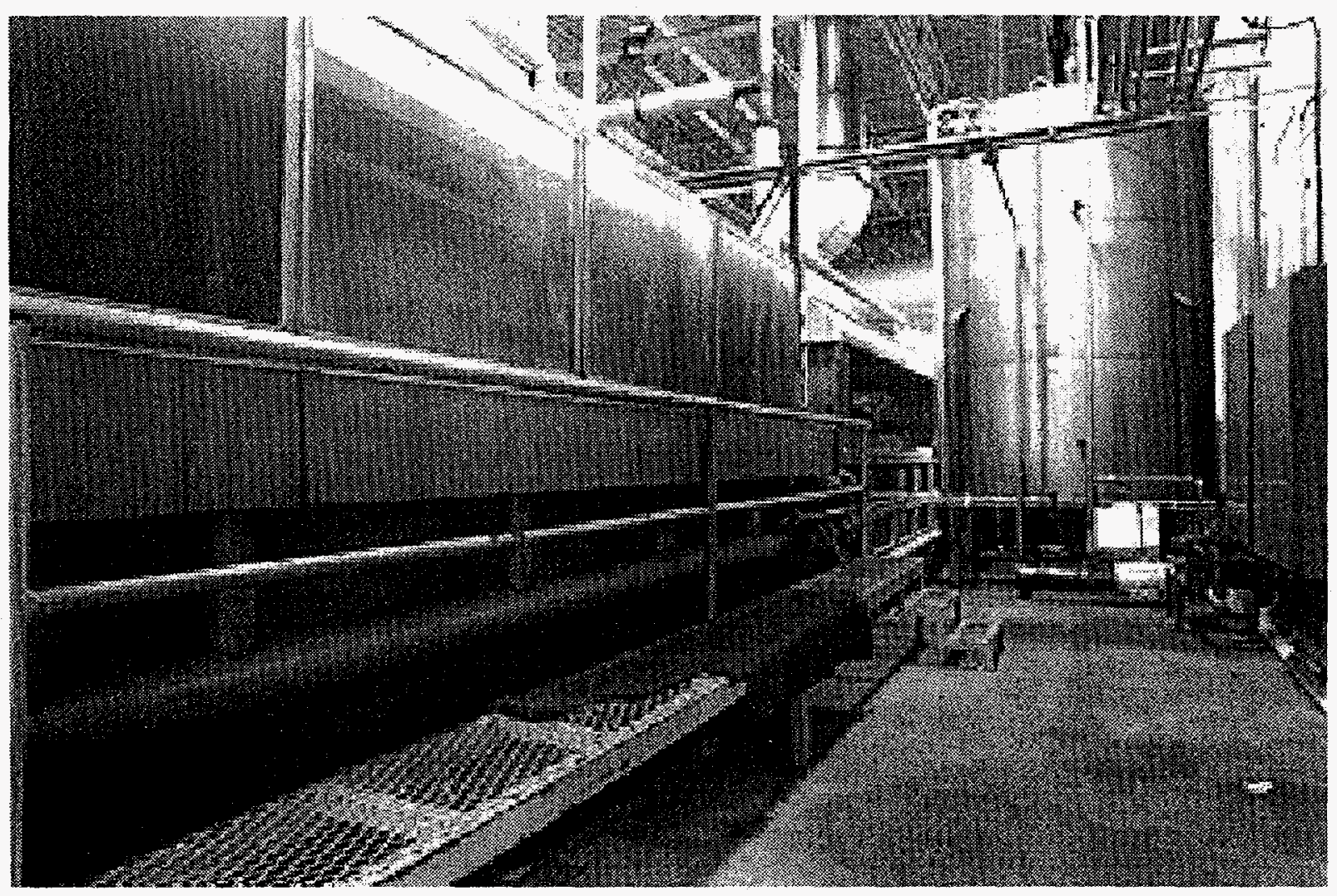

Figure 6. The Test Beck, Holding Tank, and Analysis System 


\section{The Prototype System for Automated Dyebath Analysis}

In order for the dyebath to be reused, it must be reconstituted to the proper dye concentrations for the upcoming batch. This requires that the spent bath be analyzed to determine the concentration of each component of residual dye. The analysis process consists of sample preparation, absorbance measurement, and concentration calculation. In order to support the production schedule, this analysis must be performed quickly and accurately, and an objective of the project was to automate this process.

A prototype automated analysis system was designed, fabricated, and installed in the plant. Figure 7 presents a schematic diagram of this system. A reference solution, which contains water and the same recipe of auxiliary chemicals as the dyebath but with no dyes, is pumped through one side of a dual flow cell and held there. This reference solution is prepared automatically by the system at the beginning of a dyebath reuse series. Then the dyebath sample is drawn from the holding tank, cooled, filtered, and pumped through the other side of the flow cell for examination.

Light from the same source is passed through both the sample and the reference, and the two absorbance spectra are measured in a dual-beam spectrophotometer. The difference between the two spectra represents the absorbance of the residual dyes, and the concentration of each residual dye may be calculated from calibration curves previously developed with the same instruments.

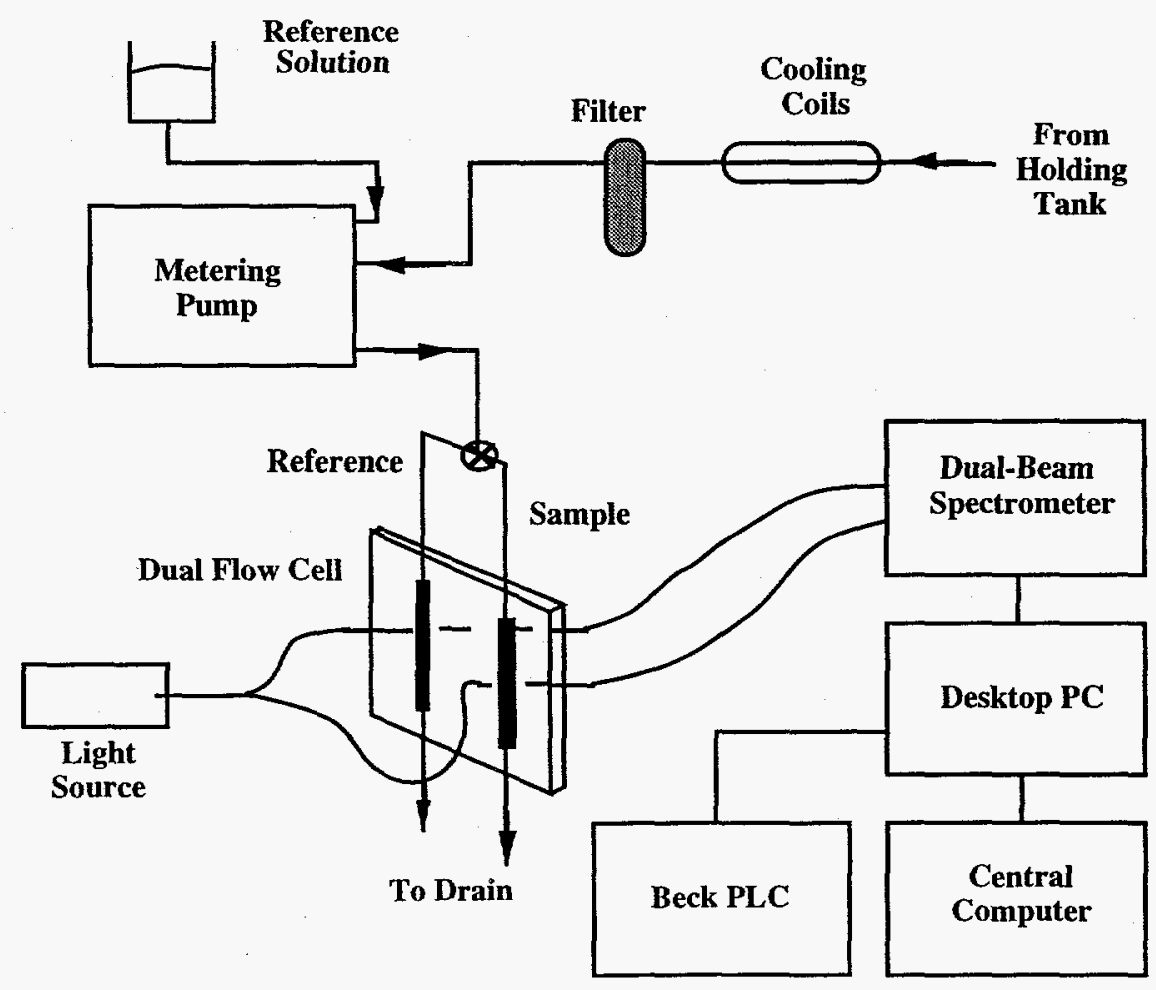

Figure 7. Components of the Automated Analysis System 
The computer which controls the analysis system and performs these calculations is connected to the PLC controlling the beck operations so that the samples are drawn at the proper time, and also to the central computer which maintains both the production schedule and the standard recipes which must be adjusted based on the analyses.

The components of the analysis system are mounted in two NEMA 4 enclosures attached to a wall behind the test beck, near the holding tank, to minimize the distance the dyebath sample is transferred for analysis. The cooling coil, filter, and sample and reference reservoirs are contained in one enclosure. The pump, flow cell, light source, and the controllers for the system are located in the other enclosure, which is air-conditioned to provide temperature and humidity conditions suitable for the electronics. Figure 8 shows the components of the analysis system contained in the enclosures. The spectrophotometer and PC are located in the control room, several hundred feet away, in order to provide a better physical environment and to facilitate the connections to the PLC and the central computer network node located there. The light passing through each side of the flow cell is carried from the enclosure to the spectrophotometer through $400 \mathrm{ft}$. of fiber optic cable.

A more detailed description of the components in the automated sampling and analysis system is presented in Appendix B. A description of the computer control of the system and the interactions between the analysis system computer, the beck PLC, and the central computer is presented in Appendix $\mathrm{C}$. The procedure for converting the spectrophotometer readings to absorbance data for the residual dyes and for using these data to calculate dye concentrations is provided in Appendix D.

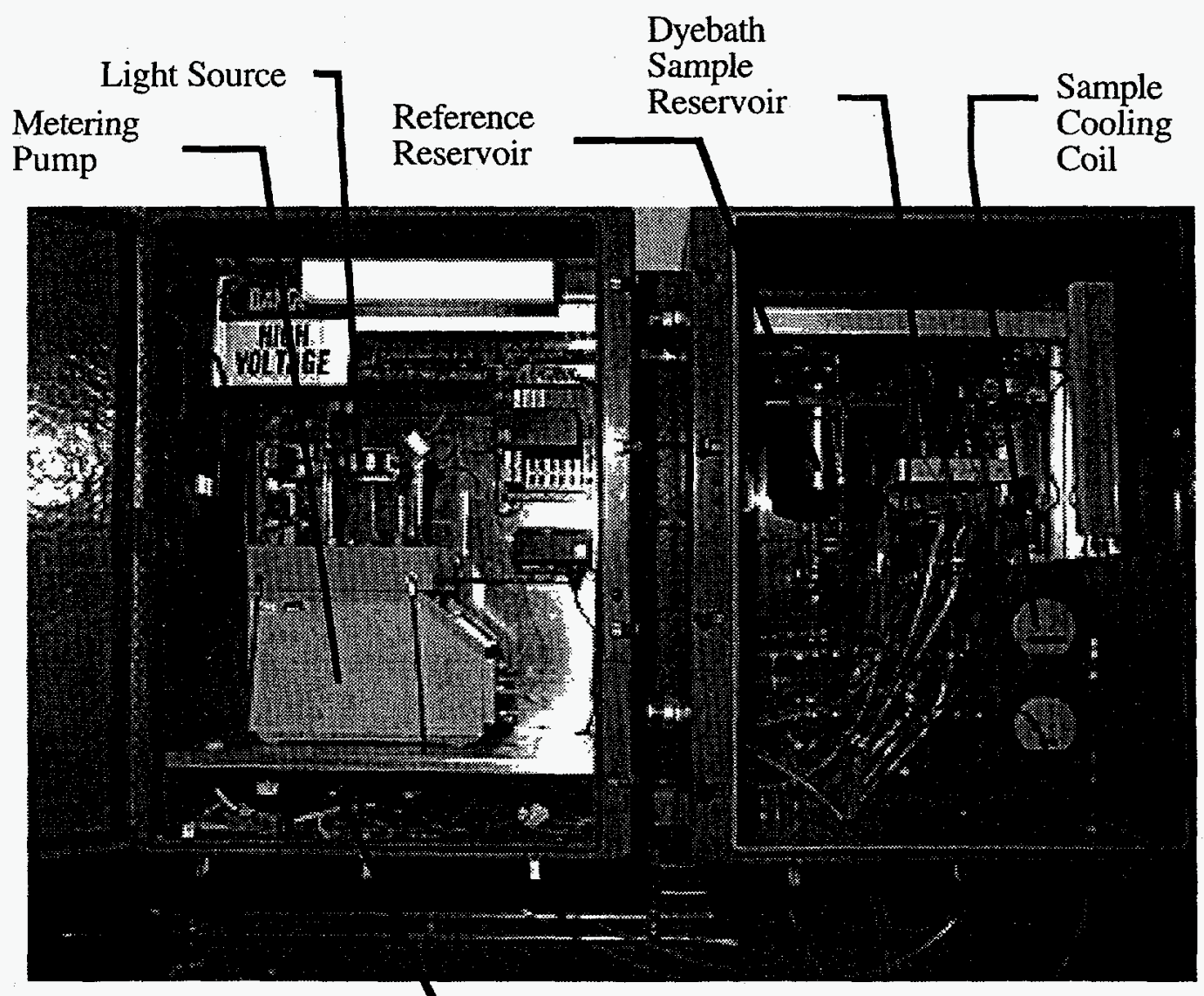

Flow Cell

Figure 8. Analysis System and Enclosures 


\section{The Demonstrations of Automated Dyebath Reuse}

The fundamental objective of this project was to demonstrate that batch dyebaths can be automatically captured, sampled, analyzed, reconstituted, and successfully reused for dyeing of nylon carpets. These demonstrations were also to establish the ability to improve the energy, environmental, and economic performance of the dyehouse operations through automated dyebath reuse.

Three sets of dyebath reuse trials were conducted under this demonstration program, with progressively increasing levels of automation. Each of these sets of trials is discussed below, with additional details provided in Appendix F.

\section{A. Non-Automated Dyebath Reuse Trial}

The first set of trials processed only two carpets. It was used primarily to check out the components of the system which had been installed and to identify modifications which were required. These trials tested the beck/tank combination and the operation of the pumps and valves. Dye concentrations in the spent dyebath were measured with the prototype analysis system under direction of the system PC, and the results were used to adjust the makeup recipe. However, the process was not performed in an automated mode, since portions of the hardware and software were not yet ready.

Before these first trials were conducted, the analysis system was calibrated using laboratoryprepared dyebath solutions, each having only a single dye component. Calibration solutions were prepared for the yellow, red, and blue dyes over a range of concentrations. The calibration data were validated by analyzing several different mixed-dye solutions of known composition. The calibration and validation data are presented in Appendix E.

The first carpet in the trial sequence was prerinsed. Simultaneously, the holding tank was filled with water, and the dyes and auxiliary chemicals were sent to the tank and mixed. After the prerinse water was drained, the bath was transferred from the holding tank to the beck, and the carpet was dyed with the standard heat-up and hold procedure. For this trial, the reference solution was mixed manually and added to the reservoir in the analysis system, where it was heated and cooled by instructions manually entered at the PC. Heating and cooling of the reference solution is required because of a change of optical properties during the first heating cycle, and the properties of the reference solution must match those of the auxiliary chemicals in the spent dyebath.

After the patch check, the dyebath was transferred to the holding tank using the hot-drop process which was previously established. Instructions were manually entered at the PC to pull a sample from the holding tank and analyze it for yellow, red, and blue dye concentrations. Based on the reported dye concentrations and the known volume of dyebath in the holding tank, the total mass of each residual dye in the tank was calculated manually. These quantities were subtracted from the standard recipe for the next carpet, and the adjusted recipe was added to the holding tank.

The second carpet was prerinsed with the cool-down rinse water from the first carpet, and then dyed using the reconstituted dyebath with the hot-start/hot-drop process. Both carpets were dyed successfully and graded first quality. Information about the style and shade of the carpets dyed in this trial is presented in Appendix F. 
This set of trials provided information on the capabilities and shortcomings of the hardware as it was installed and led to several changes in the system. A lint filter was added in the line from the beck to the holding tank to eliminate the buildup of fiber which could plug the piping and/or retain dye that would not be accounted for in analysis of the bath. Also, a water line was added to the holding tank for rinse-down as the reconstituted bath is transferred back to the beck. In spite of the lack of automation, these trials did confirm the ability to reuse the dyebath with satisfactory results with this dye chemistry system.

\section{B. Automated Dyebath Reuse Trial, Part I}

The second set of trials was performed after modifications were made to the holding tank and after the software for the automated analysis system was complete. Those trials were automated except for calculations which were to be performed on the plant's central computer. The software for those calculations was not performing properly at the time of the trials, so those few calculations were performed manually.

Prior to starting this set of trials, the calibration of the analysis system was again validated using several different mixed-dye solutions of known composition. The validation was performed to assure that there had been no change in the system since the earlier calibration, and the validation data are presented in Appendix E.

The trial consisted of two series of carpets: a four-carpet series and a five-carpet series. The styles, colors, fiber type, and dyeing results for each of these carpets and the range of dyes used in the recipes are presented in Appendix F. Specific recipes are not provided, as these are considered proprietary to Shaw Industries.

The number of carpets dyed in each series was limited by the plant's production schedule; i.e., there were no more carpets scheduled and available for dyeing which presented compatible shades and background chemical recipes for their use as the next carpet in the series. During the period of these trials, in an attempt to minimize inventory, Shaw Industries was operating on a just-in-time basis. With this system, there was a very limited number of carpets tufted and queued for dyeing, limiting the flexibility to select and schedule the carpets to optimize for dyebath reuse. The limited run durations do not indicate unsatisfactory performance of either the analysis system or the dyebath reuse process.

Several of the carpets in the trial were off shade at the time of the patch check and required adds. This is a very common practice even in standard production. After being dried, the fourth carpet in the first series was rejected as being dyed too heavy. It was subsequently redyed to a darker shade in the product line. Shaw management personnel attributed both the adds which were required and the off-shade condition of the one carpet to normal production variability rather than any aspect of the dyebath reuse process. All of the carpets were graded first quality, although the one required redyeing in order to meet standard.

Appendix F presents the analysis results, recovered dye quantity, starting (recovery) temperature, energy savings, and auxiliary chemical savings for each carpet dyed in both reuse series. The reuse dyeings were started at an average temperature of $133 \mathrm{~F}$. Based on a $60 \mathrm{~F}$ year-round average water supply temperature, the energy savings averaged approximately 2.3 MBTU per batch.

A portion of the auxiliary chemicals are lost due to dilution and to their being retained in the wet carpet when the dyebath is recovered. For this reason, thirty percent of the auxiliary chemicals were added as makeup in each batch, which translates to an average savings of 48.2 pounds of 
chemicals per batch, benefiting the process economics and reducing the pollutants released to the wastewater stream.

\section{Automated Dyebath Reuse Trial, Part II}

For the final set of trials, all of the hardware and software modifications had been completed, and the trials were performed in automated mode, including transfers of the bath between the beck and holding tank, sampling and analysis of the spent dyebath, and calculation of the adjusted recipe for reconstitution of the bath.

The analysis system was recalibrated for this trial, and the new calibration data were validated using solutions of known composition. The calibration and validation data are presented in Appendix E.

In this trial of automated dyebath reuse, a series of five carpets were dyed, with the duration of the trial again limited by availability of suitable carpets in the dyeing queue. Appendix $F$ provides data for the carpets included in the trial, the range of dyes used in the recipes, the analysis results, recovered dye quantities, bath recovery temperatures, energy savings, and chemical savings for each carpet in the series. The average process start temperature for the reuse dyeings in this series was $139 \mathrm{~F}$. The average energy savings were $2.45 \mathrm{MBTU}$ per batch. The average auxiliary chemical savings per batch were 64.8 pounds.

All of the carpets were first quality with the exception of the last one in the series, which required several adds and subsequently was downgraded and redyed. It was not clear whether the need to redye this carpet was related to normal variability or to some aspect of the analysis and reuse process. There was a substantial quantity of residual blue dye in the bath recovered from the fourth carpet (see the data in Appendix F) which could have lead to an erroneous analysis. However, such an error would have only shifted the initial dyeing of the fifth carpet, and such errors can usually be corrected by adds, which were not effective with this particular carpet. Thus, it cannot be stated conclusively whether the need for this redye should be attributed to the demonstration technology and system or not. 


\section{Results and Conclusions}

This project demonstrates that the dyebath reuse process can successfully be automated, including:

- automated transfer of the dyebath to and from a holding tank,

- automated dyebath sampling, preparation, and analysis,

- successful reuse of the dyebath for the subsequent batch, and

- integration of the analysis system with the existing automation of the production system.

In this project, automated dyebath reuse was demonstrated on nylon 6 and 6,6 carpets in a wide range of shades. The quality of carpets produced using dyebath reuse is comparable to carpets dyed using the conventional dyeing process. By reusing the dyebaths instead of discharging them to the sewer, significant amounts of water, energy and chemicals are saved.

\section{A. Water Savings}

Approximately 3,700 gallons of dyebath are recovered and reused per batch of carpet. In addition to the water saved through reuse, less water is consumed in the cool-down and rinse cycle in the dyebath reuse process than in the cool-down portion of the conventional dyeing process. The conventional process uses 1.2 becks of water ( $\sim 6,000$ gallons) compared to 1 beck $(\sim 5,000$ gallons) in the reuse process. By using less water and discharging less water to the sewer, the demand on both the water resources and the waste treatment facilities is significantly reduced.

\section{B. Energy Savings}

In the dyebath reuse demonstrations, the dyebaths were returned to the beck at an average of $136 \mathrm{~F}$. Conventional dye cycles are started at the temperature of the supply water, which has a year-round average of approximately $60 \mathrm{~F}$ in Dalton. Since the dyeings are started at an elevated temperature, less energy is required to heat the baths. The demonstrated energy savings are approximately 2.35 million BTU per reuse batch, with the computations presented in Appendix G.

There is a potential to save even more energy through process optimization. During the demonstration trials, decisions were made with significant review and consultation, leading to delays which would not be encountered once the process becomes routine. In an established reuse process, the dyebath would spend less time in the uninsulated holding tank and would be returned to the beck at a higher temperature.

\section{Chemical Savings and Pollution Prevention}

A significant amount of auxiliary chemicals are saved in the reuse process as well. Throughout the dye cycle, most of the auxiliaries remain unchanged in the bath. In conventional dyeing, all of these chemicals are discharged to the sewer. However, through reuse of the baths a substantial portion of these chemicals are recovered, and only a $30 \%$ makeup of auxiliary chemicals was used during the demonstration trials. This represents a demonstrated average savings of 54.2 pounds of 
chemicals per reuse batch. Since these chemicals are quite expensive, reuse provides a significant economic benefit as well as reducing the amount of chemicals dumped to the sewer.

During the demonstration runs, preliminary information was gathered regarding the effects of dyebath reuse on effluent quality. Appendix G presents data on COD analysis results for samples collected at the end of standard and reuse dye cycles (prior to beginning cool-down) and at the end of the prerinse cycle of the dyebath reuse runs.

Two aspects of these data are of note. First, the prerinse baths contained approximately $40 \%$ as many pounds of COD as a standard dyebath, indicating that a substantial portion of the COD loading comes from oils in the yarn finishes rather than from the dyeing chemicals. This is a known phenomena, and typically about half of the COD in batch dyeing effluent is due to yarn oils and half due to the dyeing chemicals.

The second notable item in the COD analysis data is that while the COD level in the reused dyebaths tends to rise with each reuse, there is a clear tendency for this to level off after only a few cycles. This is as expected, since most of the COD associated with the yarn is removed in the prerinse, and the other source of COD (auxiliary chemicals) is maintained constant from cycle to cycle.

\section{Direct Economic Benefits}

Analysis of the savings available through dyebath reuse indicates expected cost reductions of approximately 2.9 cents per pound of carpet for nylon 6 fiber and 3.3 cents per pound of carpet for nylon 6,6 fiber. These savings are summarized in Table 1 , and the details of the calculations are presented in Appendix G.

Table 1. Summary of Cost Savings through Automated Dyebath Reuse

\begin{tabular}{|c|c|c|}
\hline Total Savings & Cents per $\mathbf{p}$ & pet \\
\hline \multirow{2}{*}{ Auxiliary Chemicals } & Nylon 6 & Nylon 6,6 \\
\hline & 1.866 & 2.241 \\
\hline Dyes & 0.161 & 0.161 \\
\hline Energy & 0.603 & 0.603 \\
\hline \multirow[t]{2}{*}{ Water/Sewer } & 0.274 & 0.274 \\
\hline & 2.903 & 3.278 \\
\hline
\end{tabular}

These economic benefits should prove quite attractive to the carpet manufacturing industry. The potential total cost impact may be seen by considering a typical dyehouse processing 50 million pounds of carpet per year. The actual savings will depend upon the scheduling of dye operations and the resulting portion of the total production which is dyed with dyebath reuse.

Detailed economic analyses, such as payback periods, returns on investment, and net present value are all dependent upon investment costs. At this time, the market price of a commercial version of an automated analysis system has not been determined, and the actual cost to the plant for the full 
system is not clear. For example, in the demonstration one analysis system was used for one holding tank serving one test beck. The Shaw Industries plant where the demonstration was conducted has sixteen becks in production. In a plant-wide system, appropriate piping could permit becks to alternately use the same holding tanks so that fewer holding tanks would be required than the number of becks. A single analysis system could also serve multiple holding tanks. System costs would be significantly dependent upon the layout of the plant, the number and location of holding tanks, and the necessary piping and valves to support bath transfers to and from the becks.

\section{E. Summary}

Automated dyebath reuse is an economically and environmentally attractive process, which can save significant amounts of energy, water, and chemicals without compromising product quality. In addition, there are opportunities to improve upon the demonstrated process to assure that the maximum amount of dyebath is recovered and reused with the minimum dilution. During the trials, there were several adjustments made in the transfer procedure and in control of the transfer quantity. These procedures and settings could not be optimized during the limited trial runs, and significant improvement may be expected if the process is run on a continuing basis and tuned for improved water, energy, and material savings. 


\section{Recommendations for the Future}

Areas for future work related to this demonstration project include:

- commercializing and improving the analysis system,

- extending automated dyebath reuse to other fibers, dyes, and products,

- building on the automated analysis technology to provide other benefits to the textile industry, and

- reducing BOD/COD releases associated with yarn finishes.

\section{A. Technology Commercialization and Improvement}

The automated analysis system developed for this project is a prototype system built from both commercially-available and specially-fabricated parts. A commercial version of the system is required in order to implement dyebath reuse technology on a widespread basis. A commercial system should be better suited for a production environment including robustness of both hardware and software. The system is expected to be more compact and economical to produce than the prototype, as well as possibly having different capabilities which are better tailored for use in actual production, adding features which become attractive and deleting elements which prove to be unnecessary.

The demonstration project team included a university, a state government agency, and the world's largest producer of broadloom carpet. It did not include a manufacturer of process measurement and control instrumentation. During the project, preliminary conversations were held with several such manufacturers, and after the demonstration was complete, more serious discussions have been held with one major firm which has extensive background in textile process control and would be able to support the needs of the industry on even an international basis. This firm has indicated its intention to "productize" the prototype, to make the technology commercially available to the industry, and to participate jointly with the demonstration project team on some of the further investigations described below. Since arrangements have not been finalized at the time of this report, no details can be provided here.

As part of the commercialization effort, several techniques can be employed which may improve the accuracy of absorbance data obtained with the analysis system. One possible technique is to replace the existing tungsten halogen light source with a xenon flash lamp, and modify the analysis system software accordingly. The higher light output would improve the performance of the system since low light output, especially in the short wavelength region, is currently a limiting factor in performance of the analysis system. Adjustments such as automated calibration, recalibration during the test runs, and techniques to permit elimination of the reference solution may also be possible.

\section{B. Automated Dyebath Reuse in Other Textile Applications}

The technologies developed in this project can potentially be applied to a wide range of dye, fiber and product combinations, not just the acid dyeing of nylon carpet. Automated dyebath reuse can be implemented in the batch dyeing of other textile products such as yarn and fabrics. 
The automated analysis technology for acid dyes may be used with other water-soluble dyes such as direct, basic and reactive dyes to support automated dyebath reuse on different types of fibers. For some of these classes of dyes, the translation would require minimal development work. In other cases, there are significant challenges.

For example, reactive dyes are commonly used to dye cotton. During the dyeing process the dyes undergo a chemical change so that even the residual dyes are not in the same state as at the beginning of the cycle. This presents an impediment to dyebath reuse. However, this application is of significant interest, because the conventional reactive dye process consumes large quantities of salt which are released with the dye wastewater stream. This release of salt-laden wastewater is considered the single most serious water pollution problem facing the textile industry. Concepts have been investigated which would permit the conventional process to be modified to permit the baths to be reused, retaining the water, energy, dyes, and salt in the process. The potential benefits from this process improvement warrant its further investigation.

Similar automated analysis procedures can be developed for non-soluble dyes such as disperse dyes, used for polyester. Since these dyes are not soluble in water, the existing analysis system would experience analysis errors due to separation of the dyes from the water in the sample. Corrective measures would include mixing the sample with a solvent in order to place the dye in solution during the spectrophotometric analysis. The metering pump used in the analysis system was designed for high performance liquid chromatography and is capable of mixing precise quantities of liquids. The pump can be used to add solvent at known concentrations to the samples before they are delivered to the flow cell for analysis. The extensive use of polyester fibers and disperse dyes by the textile industry warrants an early development and demonstration of this automated dyebath reuse technology.

\section{C: Use of Automated Analysis for Other Process Improvements}

The automated dyebath analysis system developed in this project can also be used to monitor dye concentrations continuously throughout the dye cycle. Samples can be drawn directly from the beck for real-time concentration analysis. Continuous monitoring of the dye concentrations can provide a new process control parameter not previously available in batch dyeing. Presently, batch dyeings are controlled by monitoring time and temperature. By improving control of the dyeing process, the number of off-shade dyeings can be reduced or eliminated. This would decrease the amount of adds and redyes, which would save time and money, as well as water, chemicals and energy. Continuous concentration monitoring could also possibly lead to the development of new dyeing strategies, such as introducing the dyes throughout the cycle, rather than all at once. Continuous monitoring of dye concentrations can be applied as a control technique not only to batch dyeing, but to continuous dyeing processes as well.

\section{Additional BOD/COD Reduction Opportunity}

While the demonstration project has reduced the releases of chemicals introduced in the dyeing process itself, it has not addressed the release of oils which arrive with the carpet. The modified process has provided an opportunity for future study - since the yarn oils are now captured in a prerinse bath separate from the dyes and auxiliary chemicals, it may be much more reasonable to separate the oils from the wastewater, reuse the water for rinses, and use the oils in some beneficial manner such as fuel blending. The potential for this environmental improvement warrants further investigation. 


\section{Related Publications}

The following theses, papers, and presentations have been based upon the work discussed in this report.

James L. Clark, "Automated Dyebath Reuse," Presented at the workshop: Waste Water Pretreatment for Carpet Companies, Dalton College, Dalton, Georgia, January 1997.

James L. Clark, "Water Conservation Through Automated Dyebath Reuse," Proceedings of the 1997 Georgia Water Resources Conference, The University of Georgia, Athens, Georgia, March 1997.

James L. Clark, “Automated Analysis and Reuse of Nylon Carpet Dyebaths," Presented at the Georgia Governor's Conference on Pollution Prevention and the Environment, Atlanta, October 1997.

James L. Clark, "Automated Analysis and Reuse of Dyebaths in Manufacturing Nylon Broadloom Carpets," Presented at the EPA Region 4 Pollution Prevention/Green Manufacturing Conference, Atlanta, November 1997.

Shiqi Li, Beth White, and Wayne C. Tincher, "Analysis for Dyes Over a Wide Concentration Range for Possible Application to On-Line Measurement," accepted for publication in Textile Chemist and Colorist.

Shiqi Li, Beth White and Wayne C. Tincher, "On-Line Analysis for Dyes Over a Wide Concentration Range," Proceedings of the American Association of Textile Chemists and Colorists International Conference and Exhibition, September 1996.

Shiqi Li, "On-Line Analysis for Carpet Dyeing Processes," Thesis, Georgia Institute of Technology, February 1997.

Matthew C. Marston, "Sustainability in Process Modeling of Automated Dyebath Reuse," Thesis, Georgia Institute of Technology, September 1996.

Wayne C. Tincher, Elizabeth W. White and Shiqi Li, "System for Automated Analysis of Carpet Dyebaths," Proceedings of the American Association of Textile Chemists and Colorists International Conference and Exhibition, September 1997.

Elizabeth W. White, "Development of an Automated Analysis System for Dyebath Reuse, Thesis, Georgia Institute of Technology, October 1997. 


\section{Appendix A. The Dye Chemistry Systems Studied and the Preliminary Dyeing Trials}

Two different acid dye systems were studied. The first part of the project considered a three-dye system which represented the most common acid dyes for the dyeing of nylon carpet and which was the standard dye in use at the demonstration plant. During the course of the project, the industrial partner, Shaw Industries, the world's leading carpet manufacturer, implemented a change to a second system of acid dyes for their standard production. This second dye system was used for the remainder of the demonstration project, since it was being used by a leader in the industry and because it permitted easier comparison to the standard production in the plant. This second dye system presented significantly greater challenges, as discussed below. The successful demonstration of the automated dyebath reuse process with this dye system provides greater confidence that the technology may be adapted to a wide range of acid dye systems.

The objective of the preliminary dyeing trials was to establish that the dye cycle could be started hot and terminated hot without creating quality defects in the carpets. The several trials which were conducted are discussed below. None of these trials involved dyebath reuse, and all of them were performed prior to the installation of the holding tank and reuse system.

\section{Dye System \#1}

Dye system \#1 consists of three components identified by their Colour Index numbers: C.I. Acid Yellow 246, C.I. Acid Red 361, and C.I. Acid Blue 277. A set of hot-drop trials was conducted using this system to assess the effects which hot-dropping the bath has on carpet quality. The goal was to determine if a significant portion $(\sim 50 \%)$ of bath could be dropped to the holding tank before the cooling rinse occurred. It is important to maximize the amount of dyebath dropped at this point in order to save energy and chemicals for reuse. The results of this set of trials is shown in Table 2. The trials showed that $50 \%$ of the dyebath could be transferred to the holding tank without introducing quality problems.

The next step was to determine the temperatures at which the dyeing can be started and the dyebath can be dropped safely without affecting product quality. For the tests, it was estimated that in a dyebath reuse process, during the time the spent dyebath is transferred to the holding tank and back to the beck for the next cycle, the temperature will have decreased by roughly $30 \mathrm{~F}$ due to heat losses, dilution, and the heat capacity of the new carpet. Therefore, the start-up temperature in each of the trials was $30 \mathrm{~F}$ lower than the drop temperature. Tests covered the range of start/drop temperatures from $130 \mathrm{~F} / 160 \mathrm{~F}$ to $160 \mathrm{~F} / 190 \mathrm{~F}$ in ten degree increments. In these trials, the spent baths were not reused. The hot start-up temperatures were achieved by preheating the water prior to the dye cycle.

Since the dyeings are started hot, the amount of time required to heat the bath to the hold temperature is reduced. In the trials, the hold time was extended for variable lengths of time. This allowed added time for dye migration, to help counter some of the levelness problems associated with starting the dyeings at elevated temperatures.

The results of these trials for the first dye system are shown in Table 3. 
Table 2. Hot-Drop Trial Results

\begin{tabular}{|l|l|l|l|l|}
\hline Run & Style & Shade & Fiber & Result \\
\hline $\mathbf{1}$ & 51330 Secretariat & 34102 Dawn & Nylon 6,6 & First quality \\
$\mathbf{2}$ & 51332 Seattle Slew & 34802 Hot Pink & Nylon 6,6 & First quality \\
$\mathbf{3}$ & A3389 Picture Perfect & 42522 Gray & Nylon 6 & First quality \\
$\mathbf{4}$ & 51334 Affirmed & 34302 Spruce & Nylon 6,6 & First quality \\
$\mathbf{5}$ & 51332 Seattle Slew & 46111 Autumn Ash & Nylon 6,6 & First quality \\
$\mathbf{6}$ & 51330 Secretariat & 34109 Plaster & Nylon 6,6 & First quality \\
$\mathbf{7}$ & 51332 Seattle Slew & 46201 Banana Creme & Nylon 6,6 & First quality \\
$\mathbf{8}$ & M0115 Rare Image & 00802 Red & Nylon 6 & First quality \\
$\mathbf{9}$ & 51334 Affirmed & 34401 Periwinkle Blue & Nylon 6,6 & First quality \\
$\mathbf{1 0}$ & 51330 Secretariat & 34111 Parchment & Nylon 6,6 & First quality \\
$\mathbf{1 1}$ & A3389 Picture Perfect & 42123 Beige & Nylon 6 & First quality \\
\hline
\end{tabular}

Table 3. Hot-Start/Hot-Drop Trial Results for Dye System \#1

\begin{tabular}{|c|c|c|c|c|c|}
\hline$\overline{\text { Run }}$ & Style & Shade & Fiber & Process & $\overline{\text { Result }}$ \\
\hline 1 & $\begin{array}{l}51332 \\
\text { Seattle Slew }\end{array}$ & $\begin{array}{l}34500 \\
\text { Country Gray }\end{array}$ & $\begin{array}{l}\text { Nylon } 6,6 \\
\text { Suessen set }\end{array}$ & $\begin{array}{l}130 / 160 \\
47 \text { minute hold }\end{array}$ & First Quality \\
\hline 2 & $\begin{array}{l}51332 \\
\text { Seattle Slew }\end{array}$ & $\begin{array}{l}34500 \\
\text { Country Gray }\end{array}$ & $\begin{array}{l}\text { Nylon } 6,6 \\
\text { Suessen set }\end{array}$ & $\begin{array}{l}140 / 170 \\
49 \text { minute hold }\end{array}$ & First Quality \\
\hline 3 & $\begin{array}{l}51332 \\
\text { Seattle Slew }\end{array}$ & $\begin{array}{l}34500 \\
\text { Country Gray }\end{array}$ & $\begin{array}{l}\text { Nylon } 6,6 \\
\text { Suessen set }\end{array}$ & Standard & First Quality \\
\hline 4 & $\begin{array}{l}51332 \\
\text { Seattle Slew }\end{array}$ & $\begin{array}{l}34500 \\
\text { Country Gray }\end{array}$ & $\begin{array}{l}\text { Nylon } 6,6 \\
\text { Suessen set }\end{array}$ & $\begin{array}{l}140 / 170 \\
49 \text { minute hold }\end{array}$ & First Quality \\
\hline 5 & $\begin{array}{l}51332 \\
\text { Seattle Slew }\end{array}$ & $\begin{array}{l}34500 \\
\text { Country Gray }\end{array}$ & $\begin{array}{l}\text { Nylon } 6,6 \\
\text { Suessen set }\end{array}$ & $\begin{array}{l}150 / 180 \\
62 \text { minute hold }\end{array}$ & First Quality \\
\hline 6 & $\begin{array}{l}51332 \\
\text { Seattle Slew }\end{array}$ & $\begin{array}{l}34500 \\
\text { Country Gray }\end{array}$ & $\begin{array}{l}\text { Nylon } 6,6 \\
\text { Suessen set }\end{array}$ & Standard & First Quality \\
\hline 7 & $\begin{array}{l}51332 \\
\text { Seattle Slew }\end{array}$ & $\begin{array}{l}34500 \\
\text { Country Gray }\end{array}$ & $\begin{array}{l}\text { Nylon } 6,6 \\
\text { Suessen set }\end{array}$ & $\begin{array}{l}160 / 190 \\
66 \text { minute hold }\end{array}$ & First Quality \\
\hline$\overline{8}$ & $\begin{array}{l}51332 \\
\text { Seattle Slew }\end{array}$ & $\begin{array}{l}34500 \\
\text { Country Gray }\end{array}$ & $\begin{array}{l}\text { Nylon } 6,6 \\
\text { Suessen set }\end{array}$ & Standard & First Quality \\
\hline 9 & $\begin{array}{l}51332 \\
\text { Seattle Slew }\end{array}$ & $\begin{array}{l}34500 \\
\text { Country Gray }\end{array}$ & $\begin{array}{l}\text { Nylon } 6,6 \\
\text { Suessen set }\end{array}$ & $\begin{array}{l}160 / 190 \\
40 \text { minute hold }\end{array}$ & $\begin{array}{l}\text { Unlevel, } \\
\text { was redyed }\end{array}$ \\
\hline 10 & $\begin{array}{l}51332 \\
\text { Seattle Slew }\end{array}$ & $\begin{array}{l}34302 \\
\text { Spruce }\end{array}$ & $\begin{array}{l}\text { Nylon } 6,6 \\
\text { Suessen set }\end{array}$ & Standard & First Quality \\
\hline 11 & $\begin{array}{l}51332 \\
\text { Seattle Slew }\end{array}$ & $\begin{array}{l}34302 \\
\text { Spruce }\end{array}$ & $\begin{array}{l}\text { Nylon } 6,6 \\
\text { Suessen set }\end{array}$ & $\begin{array}{l}160 / 190 \\
60 \text { minute hold }\end{array}$ & First Quality \\
\hline
\end{tabular}


Samples of the dyebath were collected at regular intervals throughout the dye cycle for spectrophotometric analysis to determine the effect of start temperature on strike rate. Faster strike rate as a result of increased starting temperature is a major cause of unlevelness. The concentrations were measured off-line for each sample, and the data were plotted to obtain curves of concentration vs. time for the different trials. An example curve for the trials is shown in Figure 9. The figure shows that the strike rate of the dye onto the fiber increases drastically with increasing start temperature.

Based on the trials, it was determined that carpets dyed with the first dye system can safely be dyed using a start temperature of $160 \mathrm{~F}$ and a drop temperature of $190 \mathrm{~F}$. Since the only carpet that needed to be redyed had a hold time of only 40 minutes, an increase of 10 minutes over standard production, it was decided that extending the hold time by 30 minutes would allow ample time for dye migration in order to achieve a level dyeing.

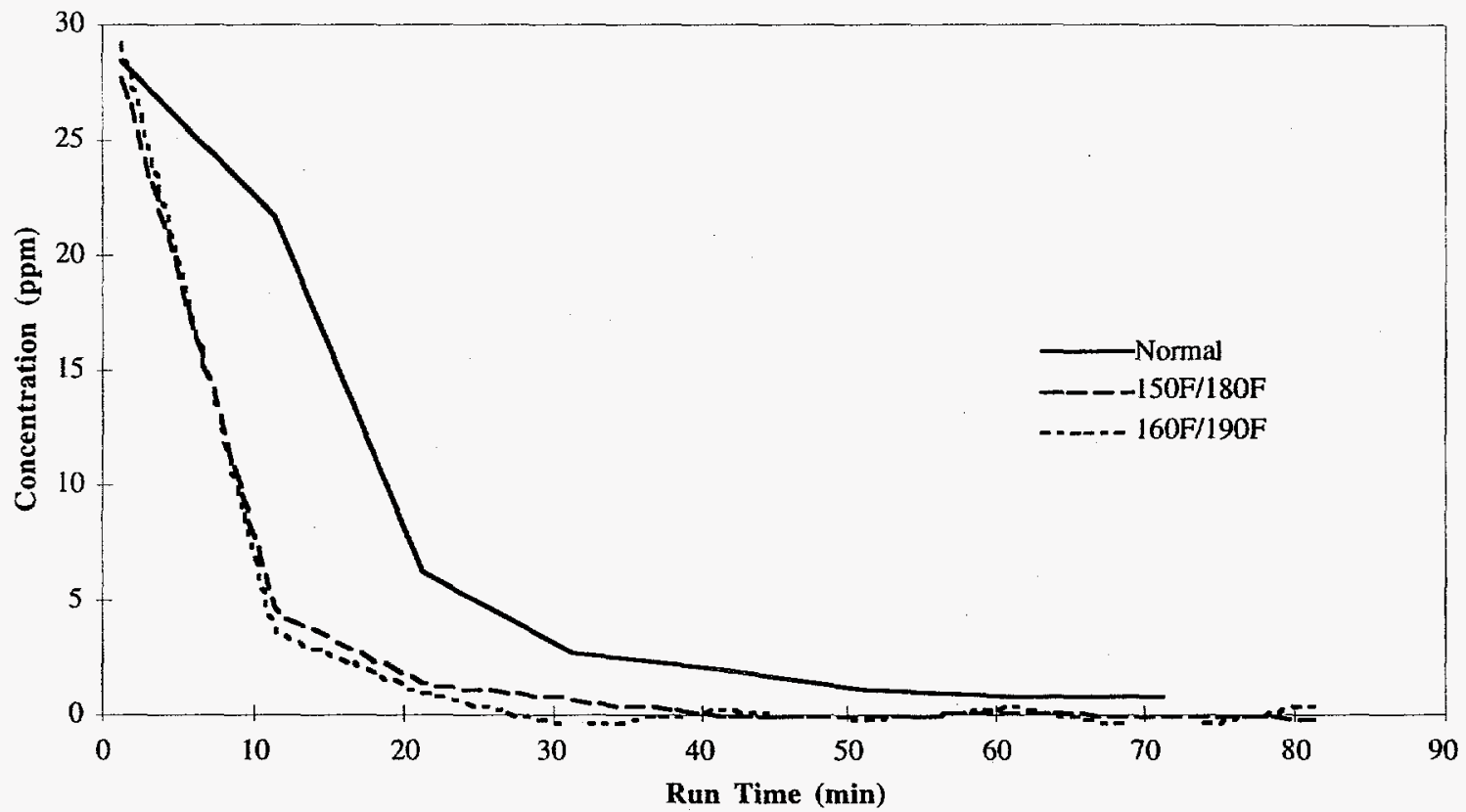

Figure 9. Dye Exhaustion for Various Process Starting Temperatures for Dye System \#1 


\section{Dye System \#2}

The second dye system is also handled by the plant as a three-dye system, but the three components are actually mixtures of a total of five dyes. The dyes are identified by their Colour Index numbers except for one dye for which such a number is not available. That dye is listed by its trade name. The three components are:

- C.I. Acid Blue 324

- A yellow dye which is a mixture of C.I. Acid Yellow 230 and Yellow A3GL

- A red dye which is a mixture of C.I. Acid Red 426, C.I. Acid Red 337, and C.I. Acid Blue 324

Hot-start/hot-drop trials were performed for carpets dyed with the second dye system. For the first set of trials, the carpets were dyed using the same hot-start/hot-drop process established for carpets dyed with the first dye system. The results in Table 4 showed that this process was unacceptable for Dye System \#2. The difficulty in achieving level dyeing with Dye System \#2 was not restricted to the hot-start/hot-drop process. Data from the table illustrate that even one of the control dyeings with the standard process gave unsatisfactory results.

Samples of the dyebaths were collected at regular intervals during the trial for later spectrophotometric analysis, as was done earlier with the trials on the first dye system. Concentration vs. time was calculated for each of the trial runs. The curves showed that the dyes used in the second system have a much faster strike rate than the dyes used in the first dye system. The faster strike rates can contribute to the unlevelness seen in the trial dyeings. An example dyeexhaustion curve is shown in Figure 10.

Table 4. Hot-Start/Hot-Drop Trial Results for Dye System \#2

\begin{tabular}{|l|l|l|l|l|l|}
\hline Run & Style & Shade & Fiber & Process & Result \\
\hline $\mathbf{1}$ & 51332 & 34302 & Nylon 6,6 & $160 / 190$ & \\
& Seattle Slew & Spruce & Suessen set & 50 minute hold & Unlevel, was redyed \\
\hline $\mathbf{2}$ & 51332 & 34302 & Nylon 6,6 & Standard & First quality \\
& Seattle Slew & Spruce & Suessen set & & \\
\hline $\mathbf{3}$ & MO586 & 00303 & $\begin{array}{l}\text { Nylon 6 } \\
\text { Superba set }\end{array}$ & $\begin{array}{l}160 / 190 \\
70 \text { minute hold }\end{array}$ & Unlevel, downgraded \\
& Melite Elegance & Green & Sulon 6 & Standard & Unlevel, was redyed \\
\hline $\mathbf{4}$ & MO586 & 00303 & Nylon & & \\
& Melite Elegance & Green & Superba set & & \\
\hline
\end{tabular}




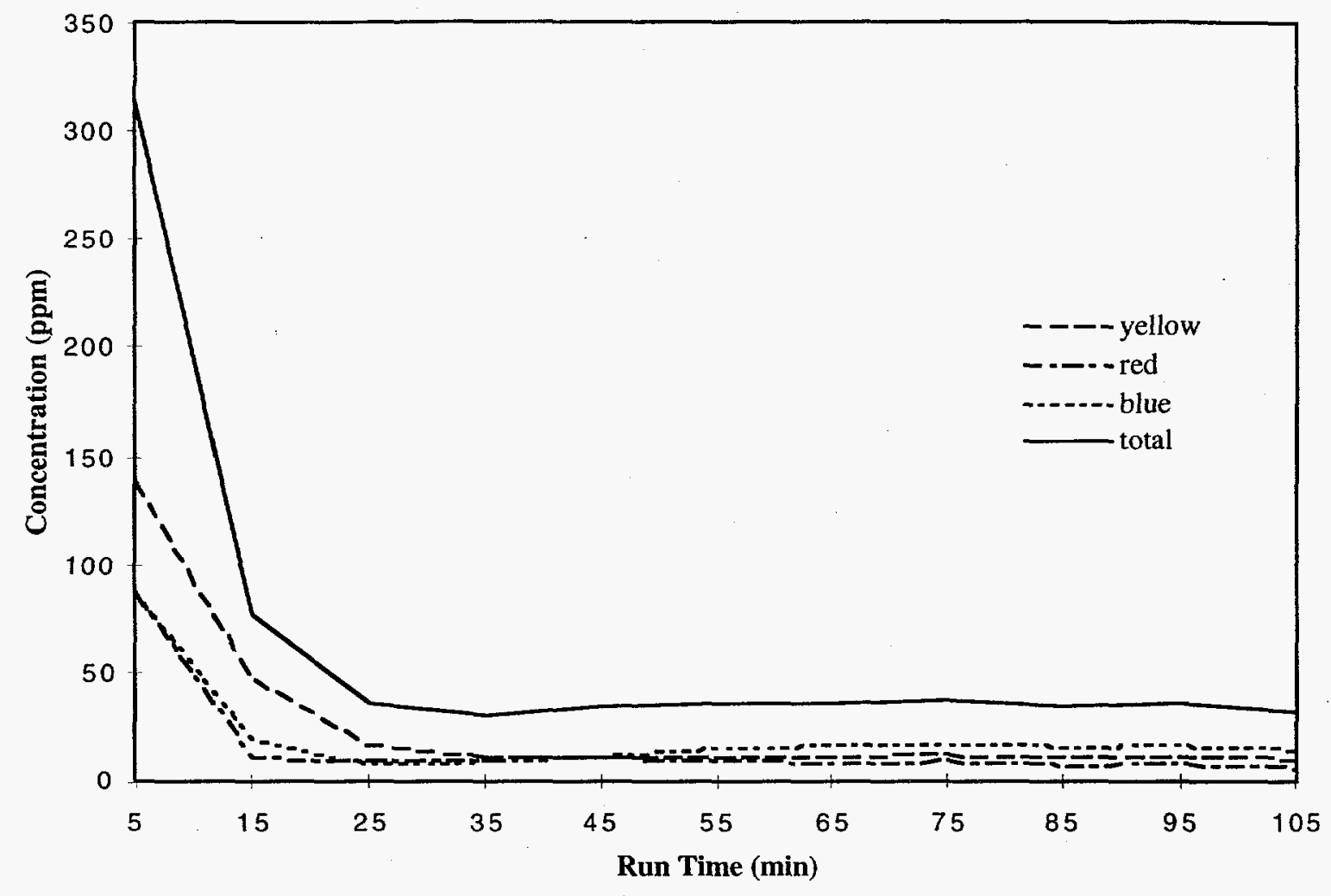

Figure 10. Dyebath Concentration vs. Time for Dye System \#2

While the plant technical and manufacturing staffs worked to improve results for standard production, several tests were conducted to improve the results with hot-start and hot-drop in order to permit successful dyebath reuse. Laboratory trials were conducted to investigate dyeing rates with each of the dyes in the two systems, and these are discussed below. Standard production dyeings were observed, and three corrective measures were established to improve the hotstart/hot-drop process. Only the first of these was required for satisfactory performance with Dye System \#1:

- Extend the hold time

- Fully mix the dyes in the bath before it touches the carpet

- Add leveling agent to a pre-rinse bath to treat the fiber before it touches the dye

These measures are discussed in more detail in Section II. Individually they significantly improved the performance of the process in Part II of the hot-start/hot-drop trials for Dye System \#2, as indicated in Table 5. At the time of these trials, without the holding tank system in place, it was not possible to test in the same run both a prerinsing of the carpet with leveling agent and fully mixing the dyes in a hot bath before introducing the carpet. The test results, however, indicated that the combination would be successful. 
Table 5. Hot-Start/Hot-Drop Trial Part II, Dye System \#2

\begin{tabular}{|c|c|c|c|c|c|}
\hline Run & Style & Shade & Fiber & Process & Result \\
\hline 1 & $\begin{array}{l}51332 \\
\text { Seattle Slew }\end{array}$ & $\begin{array}{l}34103 \\
\text { Alabaster }\end{array}$ & $\begin{array}{l}\text { Nylon 6,6 } \\
\text { Suessen set }\end{array}$ & $\begin{array}{l}\text { Hot-start with } \\
\text { fully dilute dye }\end{array}$ & First quality \\
\hline 2 & $\begin{array}{l}\text { MO586 } \\
\text { Elite Elegance }\end{array}$ & $\begin{array}{l}00106 \\
\text { Beige }\end{array}$ & $\begin{array}{l}\text { Nylon } 6 \\
\text { Superba set }\end{array}$ & $\begin{array}{l}\text { Hot-start with } \\
\text { fully dilute dye }\end{array}$ & First quality \\
\hline 3 & $\begin{array}{l}51332 \\
\text { Seattle Slew }\end{array}$ & $\begin{array}{l}34103 \\
\text { Alabaster }\end{array}$ & $\begin{array}{l}\text { Nylon 6,6 } \\
\text { Suessen set }\end{array}$ & $\begin{array}{l}\text { Hot-start with leveling } \\
\text { agent in prerinse }\end{array}$ & First quality \\
\hline 4 & $\begin{array}{l}\text { MO586 } \\
\text { Elite Elegance }\end{array}$ & $\begin{array}{l}00106 \\
\text { Beige }\end{array}$ & $\begin{array}{l}\text { Nylon } 6 \\
\text { Superba set }\end{array}$ & $\begin{array}{l}\text { Hot-start with leveling } \\
\text { agent in prerinse }\end{array}$ & First quality \\
\hline 5 & $\begin{array}{l}51332 \\
\text { Seattle Slew }\end{array}$ & $\begin{array}{l}34302 \\
\text { Spruce }\end{array}$ & $\begin{array}{l}\text { Nylon } 6,6 \\
\text { Suessen set }\end{array}$ & $\begin{array}{l}\text { Hot-start with } \\
\text { fully dilute dye }\end{array}$ & First quality \\
\hline 6 & $\begin{array}{l}\text { MO586 } \\
\text { Elite Elegance }\end{array}$ & $\begin{array}{l}00502 \\
\text { Gray }\end{array}$ & $\begin{array}{l}\text { Nylon } 6 \\
\text { Superba set }\end{array}$ & $\begin{array}{l}\text { Hot-start with } \\
\text { fully dilute dye }\end{array}$ & First quality \\
\hline 7 & $\begin{array}{l}51332 \\
\text { Seattle Slew }\end{array}$ & $\begin{array}{l}34302 \\
\text { Spruce }\end{array}$ & $\begin{array}{l}\text { Nylon 6,6 } \\
\text { Suessen set }\end{array}$ & $\begin{array}{l}\text { Hot-start with leveling } \\
\text { agent in prerinse }\end{array}$ & $\begin{array}{l}\text { Unlevel (due to } \\
\text { equipment } \\
\text { failure) }\end{array}$ \\
\hline 8 & $\begin{array}{l}\text { MO586 } \\
\text { Elite Elegance }\end{array}$ & $\begin{array}{l}00502 \\
\text { Gray }\end{array}$ & $\begin{array}{l}\text { Nylon } 6 \\
\text { Superba set }\end{array}$ & $\begin{array}{l}\text { Hot-start with leveling } \\
\text { agent in prerinse }\end{array}$ & Unlevel \\
\hline 9 & $\begin{array}{l}51332 \\
\text { Seattle Slew }\end{array}$ & $\begin{array}{l}34104 \\
\text { Bisque }\end{array}$ & $\begin{array}{l}\text { Nylon } 6,6 \\
\text { Suessen set }\end{array}$ & Standard & First quality \\
\hline 10 & $\begin{array}{l}\text { MO912 } \\
\text { Cavatina }\end{array}$ & $\begin{array}{l}00900 \\
\text { Surprisingly } \\
\text { Purple }\end{array}$ & $\begin{array}{l}\text { Nylon } 6 \\
\text { Suessen set }\end{array}$ & Standard & First quality \\
\hline
\end{tabular}

\section{The Modified Dyeing Process}

Based on the results of the hot-start/hot-drop trials, and the need for a prerinse cycle, the following modified dyeing process was developed and used in the dyebath reuse trials:

\section{i. Prerinse the first carpet in the sequence}

Roll carpet onto reel

Back carpet into beck

Sew carpet and fill beck to 65 inches

Turn on circulation pump and reel

Let carpet prerinse for 5 minutes

Dump prerinse bath to the drain

ii. Prepare first dyebath (done simultaneously with the prerinse)

Fill holding tank with water

Add defoamer to holding tank

Add auxiliary chemicals to holding tank

Turn on circulation pump for 10 minutes to mix chemicals

Draw reference sample from holding tank and prepare for analysis

Drop dyes to holding tank

Mix bath for 10 minutes in the holding tank 
iii. Dye first carpet

Transfer bath from the holding tank to the beck and flush residual bath from holding tank

Turn on beck recirculation pump and reel

Heat bath to the hold temperature

Maintain bath at hold temperature for standard time

Perform patch checks and adds as necessary

iv. Transfer bath to holding tank

Pump to holding tank until beck reaches 50 inches

Fill beck to 56 inches to cool bath and carpet

Pump to holding tank until the level in the tank reaches 105 inches

Dump residual dyebath to the drain

Fill beck to 65 inches to further cool the carpet and aid in pulling

v. Pull carpet from beck

vi. Analyze spent dyebath (simultaneously with pulling carpet from beck)

Pull sample from holding tank

Analyze sample

Calculate concentration

Calculate makeup auxiliary chemicals and makeup dyes

vii. Prerinse carpet with cooling water from previous carpet

Drop water level in beck to 40 inches

Roll carpet onto reel

Back carpet into beck

Sew carpet

Add leveling agent

Turn on circulation pump and reel

Let carpet prerinse for 5 minutes

Dump prerinse bath to the drain

viii. Prepare dyebath for reuse (simultaneously with vii)

Add defoamer to holding tank

Prepare makeup chemicals and dyes and add to the holding tank.

Turn on holding tank circulation pump and mix bath for 10 minutes

ix. Dye carpet

Transfer dyebath from the holding tank to the beck

Heat to the hold temperature

Maintain bath at the hold temperature for the amount of time in a standard dyeing plus 30 minutes

If the bath is to be reused, the cycle is started again from step \# iv. If the bath is not to be reused, a standard cool-down cycle takes place; then the bath is dumped to the drain.

\section{Laboratory Dyeing Tests}

Problems experienced in the early dyeings in the carpet facility led to a number of studies to better characterize the dyes being used to dye nylon 6 and nylon 6,6. Exhaustion curves were obtained for the eight acid dyes in the two dye systems on both nylon fiber types with the dyeings initiated at room temperature $(70 \mathrm{~F})$ and at elevated temperature $(160 \mathrm{~F})$ to simulate the regular and reuse dyeing conditions. These studies were conducted on an Ahiba Texomat laboratory dyeing machine 
with dye concentrations being monitored continuously using an early version of the analytical system. This early version was similar to the system later developed for the plant except that a commercial (Shimadzu SPD-M6A) photo diode array based detector and flow cell were employed.

The pump delivering dye bath was set at a flow rate of $10 \mathrm{ml} / \mathrm{min}$. Background solutions (which contained the same chemicals except for the dyes and at the same concentrations as the dye baths being measured) were used as the reference against which the dye baths were measured. The spectral range of the photo diode array was 380-670 $\mathrm{nm}$. The measurement wavelengths were set at 3 points $(410,510$ and $610 \mathrm{~nm})$, which were near the peak absorbance positions of the blue, red and yellow dyes used, respectively. The bandwidth was $10 \mathrm{~nm}$ for the absorbance measurement. The reference solution was pumped first as a reference. After measuring for 0.5 minute, the input ports were switched to pump either dye solution or both reference and dye solution at a controlled ratio. The sample solution was run at least 2 minutes to get stable absorbance data. The measurement data were stored for subsequent analysis.

Exhaustion curves for the eight acid dyes were obtained over the entire course of the dyeing cycle. Two typical exhaustion curves for C.I. Acid Blue 277 (from Dye System \#1) and C.I. Acid Red 337 (from Dye System \#2) dyeings of nylon 6 and 6,6 at both room temperature start and elevated temperature start are shown in Figure 11 and Figure 12.

The effects of dyeing conditions on the initial dyeing rate are clear from these figures. The dyeing rates were higher for nylon 6,6 than for nylon 6 . This is the reverse of the expected behavior and was probably due to the differences in $\mathrm{pH}$ in the two processes. Ammonia is added at the beginning of nylon 6 dyeings ( $\mathrm{pH}$ about 8 ) to retard the initial rate of dye adsorption. Ammonia was not a standard chemical addition to the nylon 6,6 dyeings. The dyeing rates were higher in hot-start processes than in cold-start ones. This certainly could contribute to the observed problems of unlevelness in hot-start dyeings in some of the early plant trials.

The initial dyeing rate is particularly important in dyeing processes. High initial dyeing rates can cause unlevelness of the dyed textiles. In the laboratory tests, the initial dyeing rate was determined by the average dyeing rate in the first three minutes of the dyeing process. A uniform exhaustion rate among all of the dyes in a recipe (dye compatibility) is very important also for uniformity and repeatability of the dyeing process.

The initial dyeing rates in the laboratory dyeings of nylon 6 and 6,6 with both dye systems with both normal and hot start are shown in Figure 13 and Figure 14. The uniformity of initial dyeing rates for Dye System \#1 under the wide range of conditions examined (compatibility) indicates that this is a very robust group of dyes for which shade and levelness should be achievable over a range of dyeing conditions. The wider range of initial dyeing rates for Dye System \#2 suggests that these dyes will be more susceptible to unlevelness and shading problems under varying dyeing conditions. 


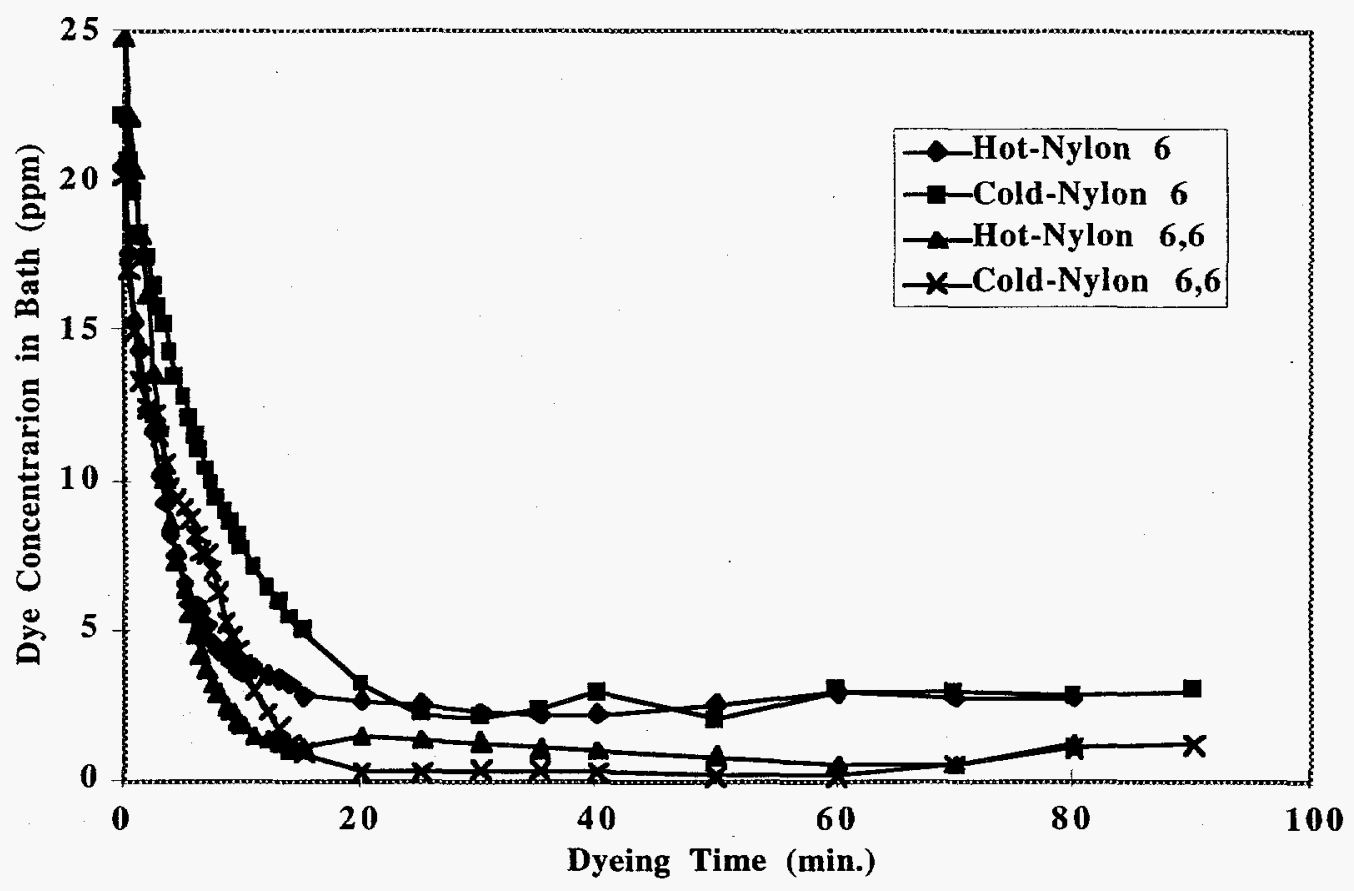

Figure 11. Dye Exhaustion for Blue Dye from Dye System \#1

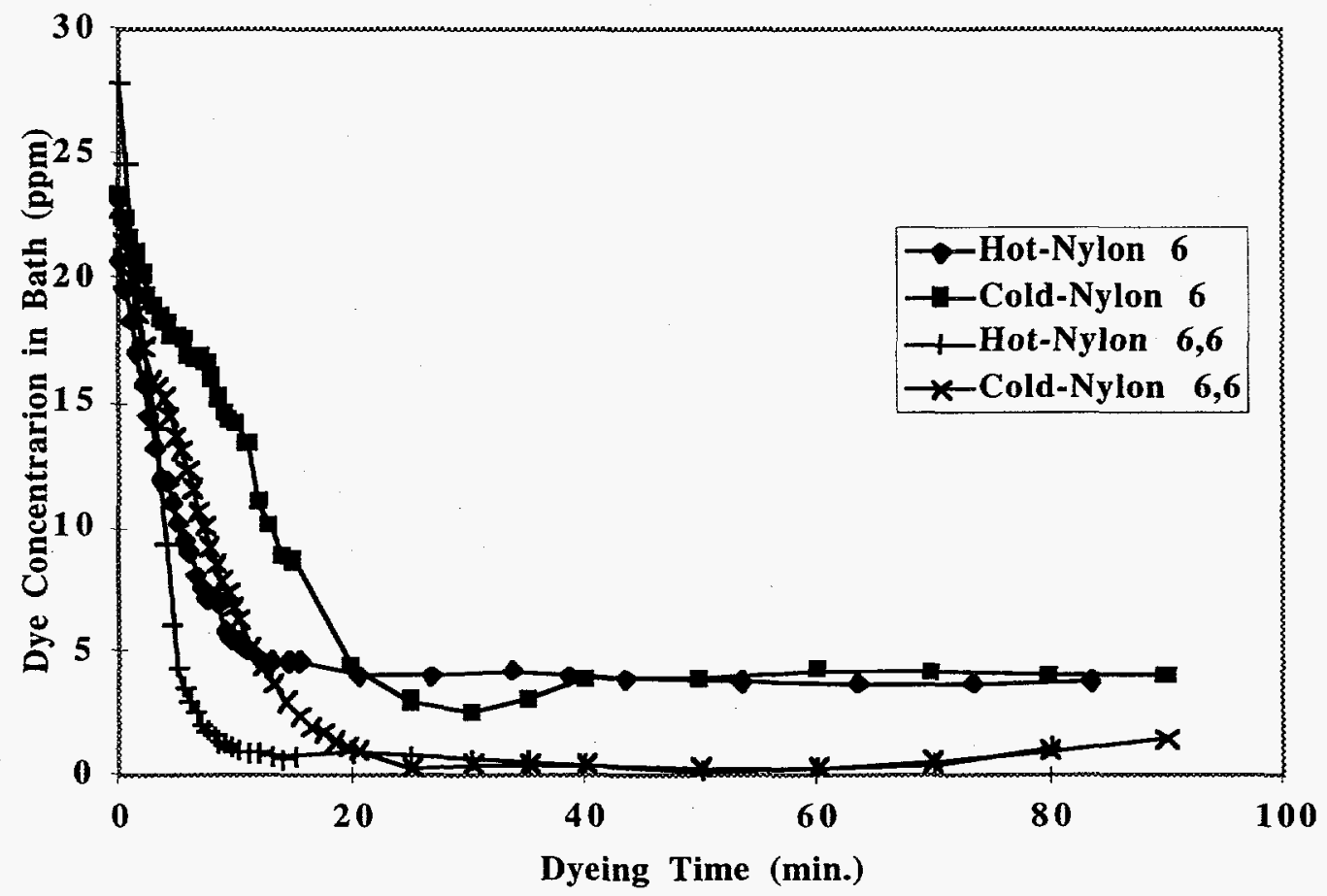

Figure 12. Dye Exhaustion for Red Dye from Dye System \#2 


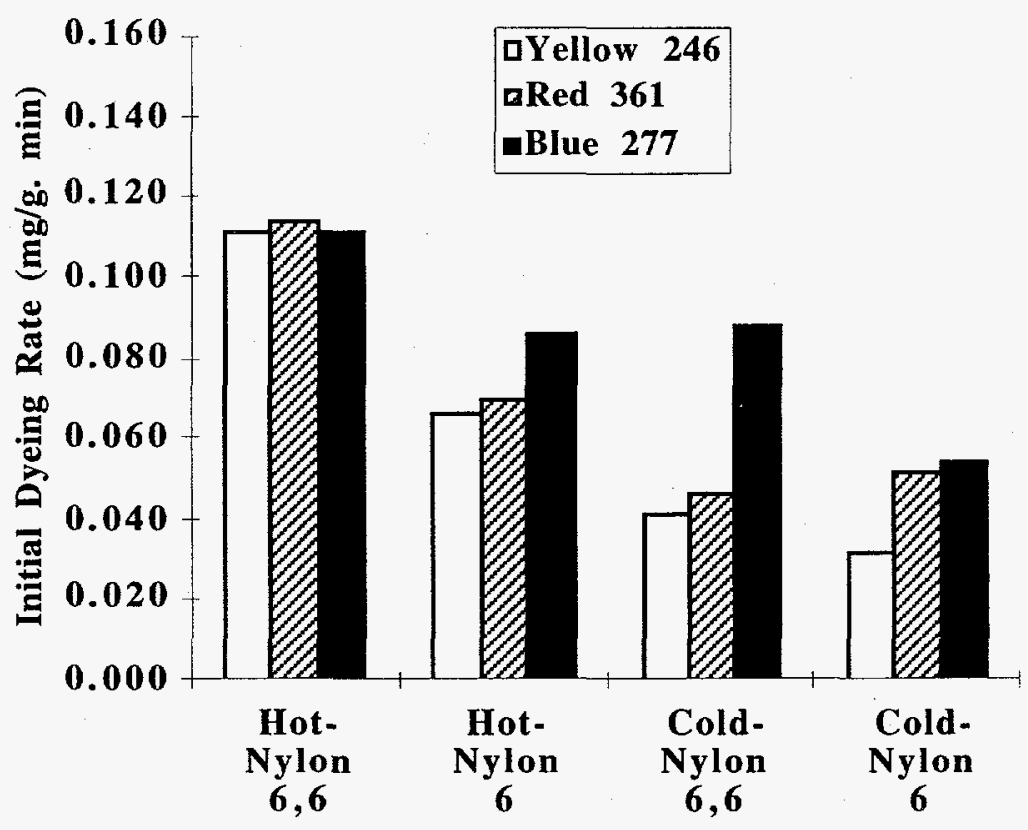

Figure 13. Initial Dyeing Rates for Dye System \#1

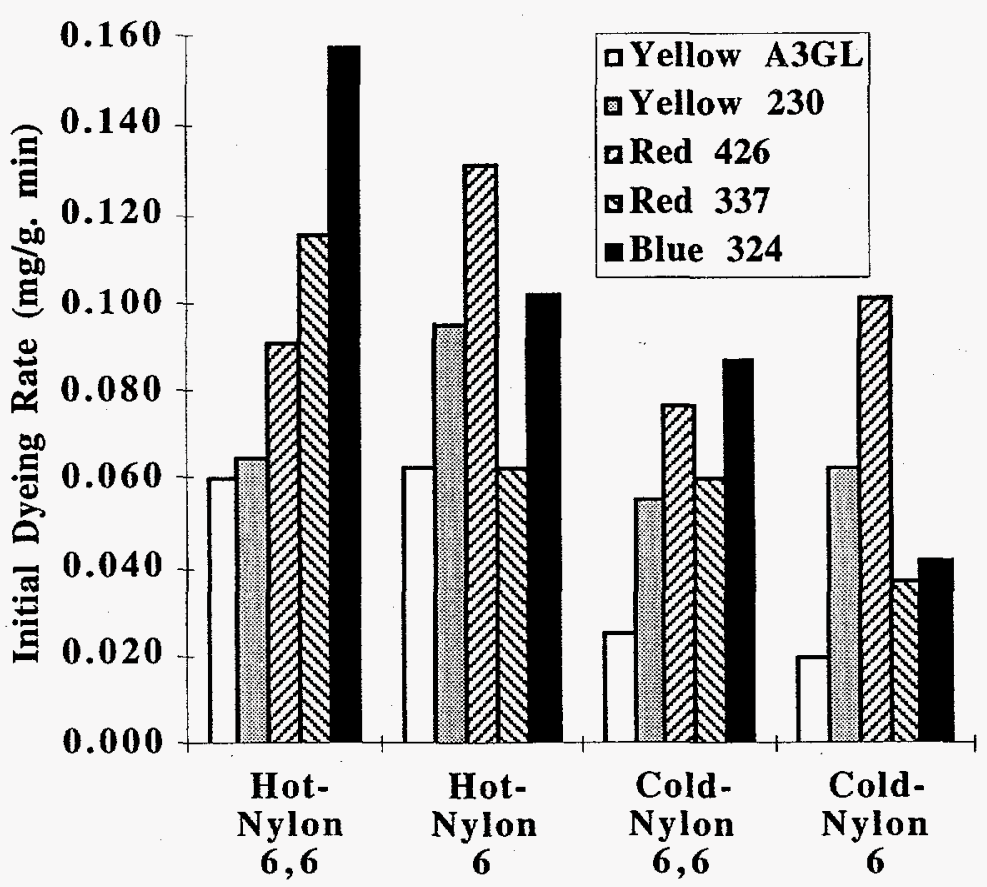

Figure 14. Initial Dyeing Rates for Dye System \#2 


\section{Appendix B. Hardware Components in the Prototype Analysis System}

\section{Sample Preparation}

Samples of the spent dyebath in the holding tank are drawn from the circulation line on the tank by a 1/2 gpm transfer pump and delivered through a Y strainer and a backflushable filter. A flow rate in this range is desired in order to purge the transfer lines quickly and expedite the analysis procedure. Only a few milliliters of the bath are required for the actual analysis. The bulk of the flow is sent to the drain for the few minutes the pump is running in this sample-and-analyze step, since the plumbing needed to return the flow to the tank is not justified by the few gallons which are lost. A small portion of this flow is diverted for preparation and analysis.

In order for samples of the spent dyebath to be analyzed properly, they must be cooled and filtered, and flow must be maintained without allowing air bubbles to enter the flow cell. The flow passes through a heat exchanger which consists of concentric tubes (1/8" stainless steel inside $1 / 4$ " copper) coiled in a helix. The dyebath flows in the inner tube and is surrounded by counterflowing water in the outer tube.

The cooled dyebath sample enters the bottom of a glass reservoir, shown in Figure 15, with a significant portion overflowing the reservoir to the drain. The incoming flow surrounds a porous metal filter positioned in a recess in the bottom of the reservoir, and samples for analysis are extracted from the reservoir through the filter. This configuration assures that the analysis examines the most recent flow into the system.

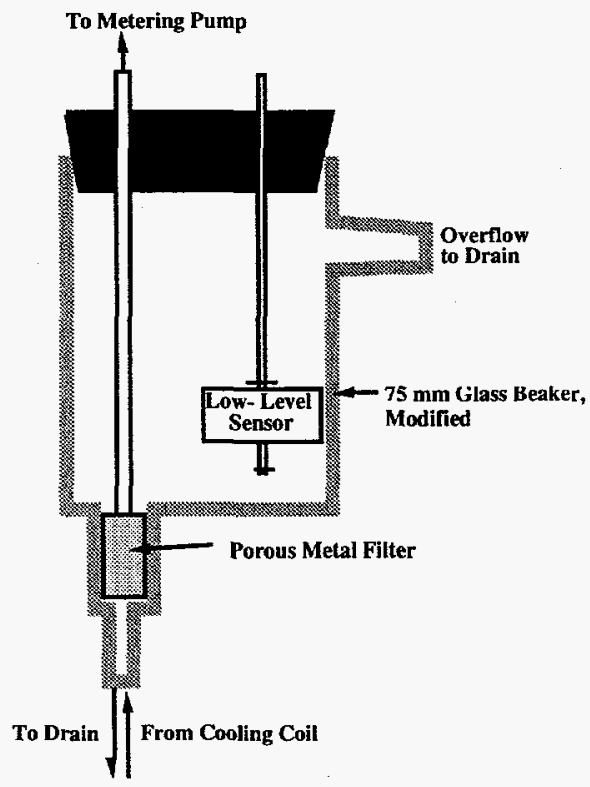

Figure 15. Sample Reservoir

The reservoir and overflow system was provided in case the metering pump were temporarily to draw samples at a greater rate than the incoming flow. The reservoir includes a low-level sensor which is monitored by the control system to assure that the metering pump does not draw the level low enough to expose the filter and permit air to enter the system. The procedure for drawing a 
new sample begins by emptying the previous dyebath from the reservoir back through the inlet and through a drain valve until a low-level condition is reached. Then the valve is closed, and the transfer pump delivers the new dyebath until the reservoir is filled to overflowing, so a fresh sample may be drawn by the metering pump. It is very important that the sample be thoroughly filtered, since any particulate matter in the flow cell at the time of the analysis will scatter light and cause errors in the analysis.

\section{Reference Solution Preparation}

In addition to the sample to be analyzed, a reference solution must be prepared. This solution contains all of the auxiliary chemicals in the dyebath, but does not include the dyes. This solution is needed for the spectrophotometric analysis of the dyebath. The two standard background formulations used in the trials are shown in Table 6 . These formulas may vary slightly according to the product.

\section{Table 6. Standard Background Formulas for Nylon 6 and 6,6 Carpets}

\begin{tabular}{|l|c|c|}
\hline Chemical & $\begin{array}{c}\text { of fiber weight, } \\
\text { Nylon 6 }\end{array}$ & $\begin{array}{c}\text { \% of fiber weight, } \\
\text { Nylon 6,6 }\end{array}$ \\
\hline Defoamer & 0.50 & 0.50 \\
Antichlor agent & 0.13 & 0.17 \\
Water softener & 0.75 & 0.96 \\
Chelating agent & 1.25 & 1.61 \\
Leveling agent & 1.00 & 0.96 \\
Lubricant & & 1.29 \\
pH Buffer & 2.00 & 1.00 \\
pH control & 0.50 & \\
pH control & 0.30 & \\
Dye retardant & & \\
\hline
\end{tabular}

The reference solution is obtained before the very first carpet in the sequence is dyed. After the holding tank is filled with water and the auxiliary chemicals are added, the circulation pump is turned on to mix the chemicals. A portion is then pulled the same way a dyebath sample would be pulled. However, it is routed to a separate reference-solution reservoir rather than through the heat exchanger. After the reference solution is pulled, the dyes are added to the holding tank and mixed, and the first carpet can then be dyed.

Because the optical properties of the auxiliary chemicals in the dyebath change upon the first heating and cooling cycle, the reference solution must be heated, then cooled in the same manner as the dyebath in a dye cycle. The stainless steel reservoir for the reference solution is insulated and equipped with a thermocouple, an electric resistance heater, and a cooling coil through which cooling water is passed and which is immersed in the reservoir. The electric heater heats the outside of the reservoir, bringing the solution to the proper temperature, and holds it at that temperature. After the specified hold period, the heating is stopped and water is circulated through the cooling coil to bring the solution back to room temperature. Then the solution is drawn from a line at the bottom of the reservoir and passes through a porous metal filter and on to the metering pump.

There is a three-way valve on the discharge line of the metering pump which allows the solution being pumped to be routed to either the sample side of the flow cell or the reference side. 
All of this sample preparation equipment is located at the holding tank. The items located after the backflushable filter are contained in one side of a wall-mounted, double enclosure, as shown in Figure 8 in Section III.

\section{Analysis System Equipment}

The analysis system uses absorbance spectrophotometry to determine the concentration of each of the three component dyes (yellow, red, and blue) in the spent dyebath. The system consists of a light source, a metering pump, a dual flow cell, fiber optic cables and a dual beam spectrophotometer which sends data to a personal computer for analysis.

The pump chosen is a Constametric 4100 manufactured by Thermo Separation Products. It has four inlet ports that are capable of pumping precise ratios of up to four solutions at a time, at flow rates of up to $10 \mathrm{ml} / \mathrm{min}$. This allows the reference solution to be drawn from its reservoir through one inlet port, while the spent dyebath from the holding tank is drawn from the sample reservoir through another port. The pump also allows the option of diluting samples with reference solution if the concentrations are too high to be accurately measured using Beer's Law.

The light source used is a 3,100 K LS-1 tungsten halogen lamp manufactured by Ocean Optics, Inc. The spectral output of the lamp is shown in Figure 16. The light coming from the light source is split into two beams with a 200 micron Y-cable. Each side of the flow cell is illuminated by one side of the Y-cable.

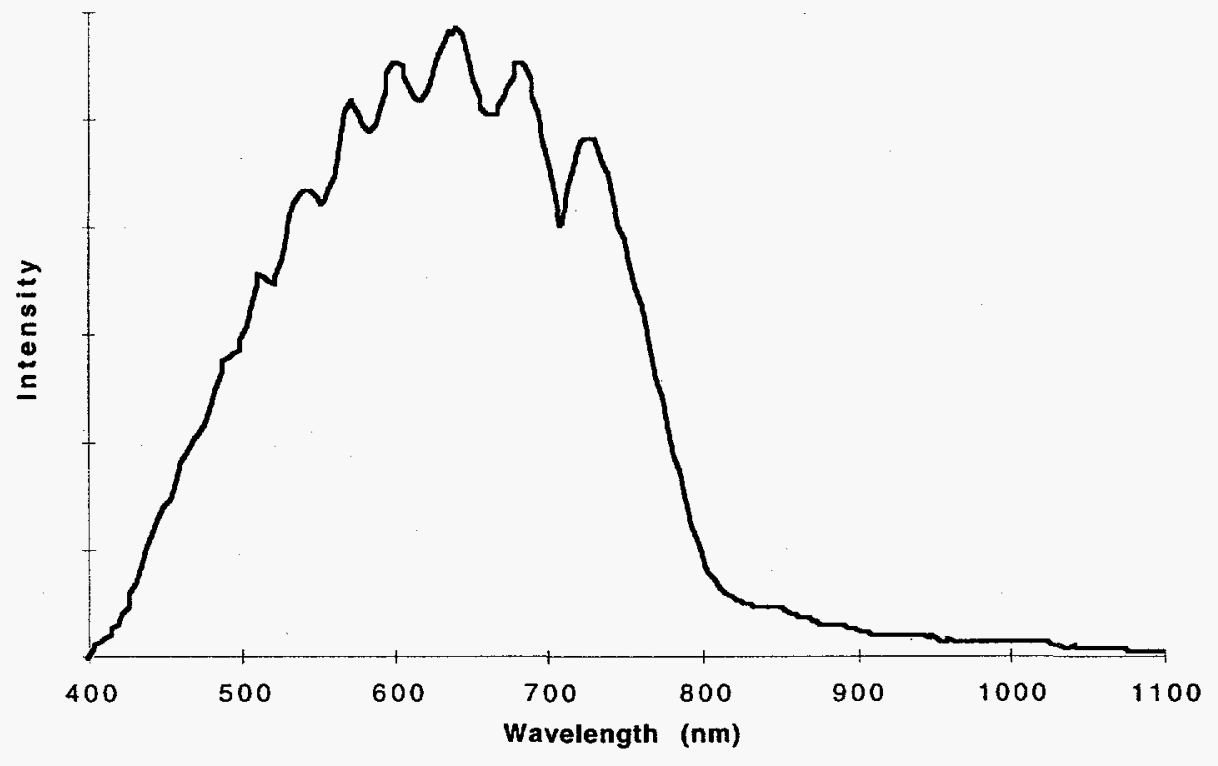

Figure 16. Spectral Output of Light Source

The dual flow cell is manufactured by Thermo Separation Products and is illustrated in Figure 17. It has two identical quartz cells with a path length of $1.0 \mathrm{~cm}$. One side is used for the reference solution, and the other side is used for the dyebath samples. A three-way valve controlling the output of the metering pump is turned on so that the reference side of the cell can be filled with the reference solution. This solution remains in the reference side of the flow cell for the entire reuse 
sequence. At the beginning of each dyebath reuse sequence, a new reference sample is obtained. The three-way valve is switched so that the sample of spent dyebath is pumped through the sample side of the flow cell. A flow rate of $10 \mathrm{ml} / \mathrm{min}$ is pumped for three minutes to flush the cell out, then at $2.5 \mathrm{ml} / \mathrm{min}$ while the measurements are taken. Light transmitted through the cells is sent through a set of 62.5 micron cables approximately 400 feet long to the control room to the spectrophotometer.

A flow cell holder has been designed to connect the fiber optic cables to the cell as shown in Figure 18. Since the flow cells are spaced only 1/4 inch apart, SMA connectors on the ends of the cables are too wide to be placed side by side in order to illuminate each side of the flow cell. The connectors had to be removed from the cable ends, and an adapter added to hold the cables firmly in position.

The detector used is a dual beam SD 1000 spectrophotometer manufactured by Ocean Optics, Inc.
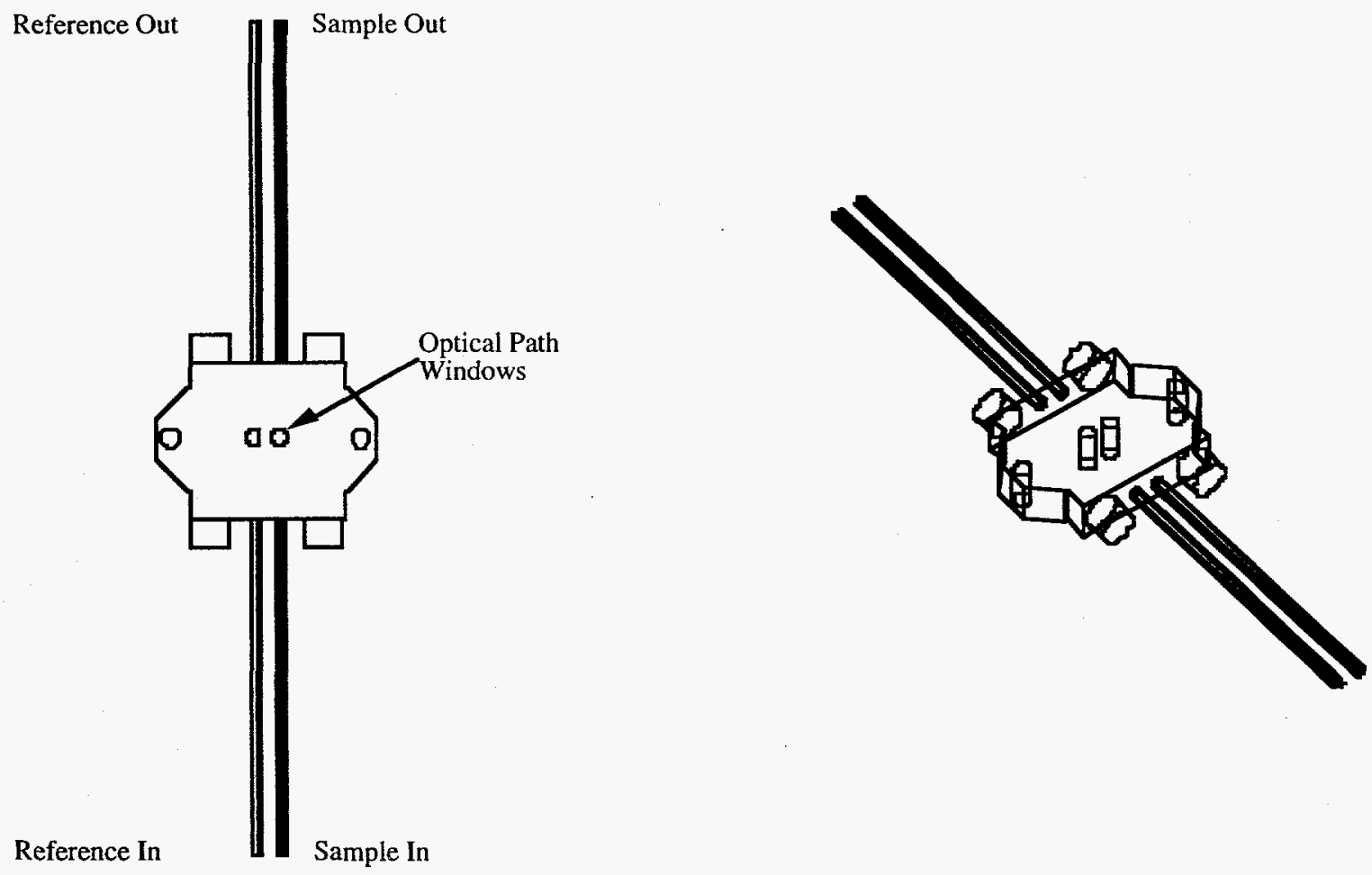

Figure 17. Flow Cell 


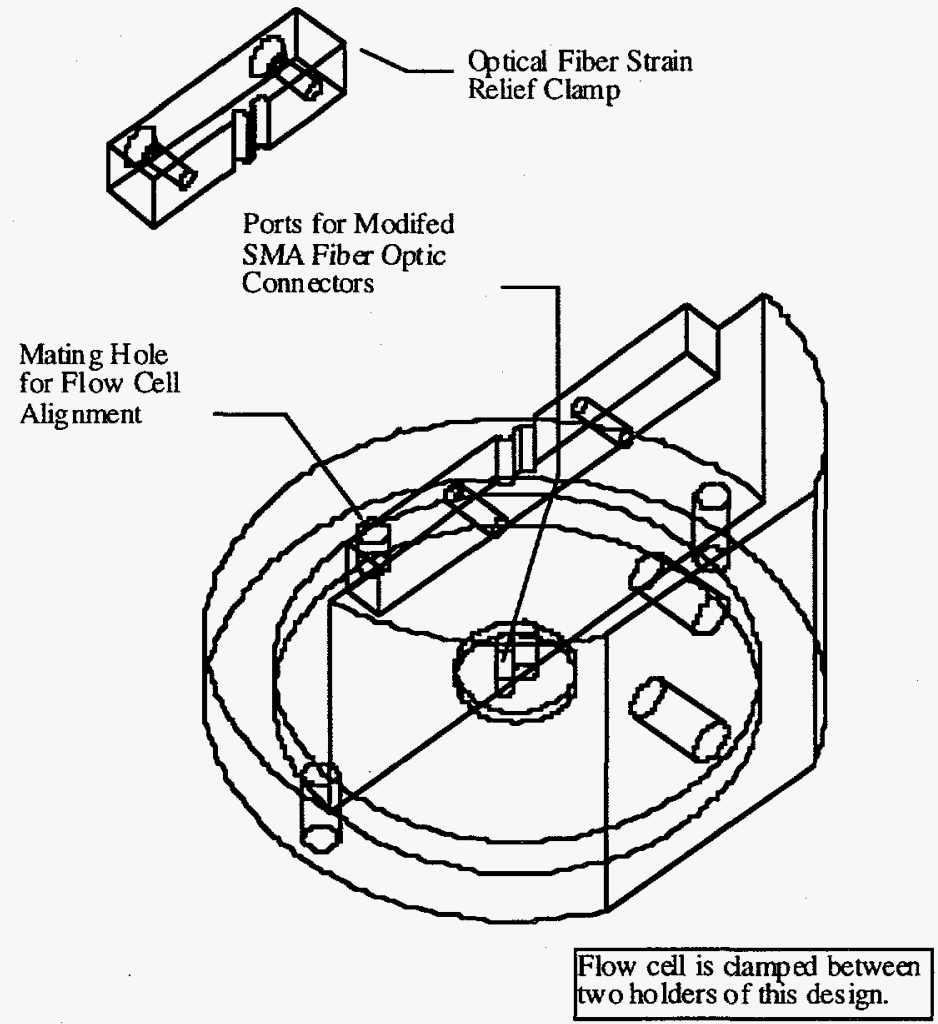

Figure 18. Flow Cell Holder 


\section{Appendix C. Computer Control of the System and the Process}

Successful implementation of dyebath reuse requires that the system be fully automated. This includes automation of the analysis system as well as integration of the system with the plant's existing production system.

Custom developed software is used to control the operation of the analysis system, including the sampling valves and pumps, the operation of the spectrometer, and the preparation of the reference solution. The software also allows the analysis system to communicate via File Transfer Protocol (FTP) with the plant's central computing system, a Digital Equipment Corporation VAX, and through the use of switch signals with the beck's programmable logic controller (PLC). The VAX system collects data on all of the dyeings as well as calculates formulas for each dyeing. It also notifies the PLC which one of a variety of standard dye cycles should be used for each process. The PLC controls the operation of the beck throughout the dyeing cycle, including control of pumps, valves, drains, water level, and temperature.

Before each dyeing in a reuse sequence is started, the VAX creates a two-character start file. The first character is either a 0,1 or 2 . A " 0 " indicates that the dyeing is the first in the reuse sequence. A " 1 " indicates that the dyeing is a reuse dyeing, but not the first or last in the sequence. A " 2 " indicates that the dyeing is the last in the reuse sequence, and that the dyebath is to be dumped to the drain after the cool-down. The value of this character is determined from data entered manually at a terminal in the beck control room before each dye cycle.

The second character is either 0 or 1 . A " 0 " means that the carpet to be dyed is made of nylon 6 . A " 1 " means that the carpet is made of nylon 6,6 . This allows the analysis system to determine which set of calibration curves to use for the concentration calculation. The calibration curves are slightly different because different background chemical recipes are used for the different polymers. The carpet type is determined from information already stored in the VAX.

The analysis system reads this start file and relays the information to the PLC. The PLC then controls the actual dyeing process based on the location of the dyeing in the reuse sequence, as determined from the first character of the start file. The PLC software has been modified so that it adjusts the steps in the dyeing process for each of the three possible processes.

After the dye cycle is complete and the dyebath has been sent to the holding tank, the analysis system software calculates the concentration of the dyes in the tank. This information is stored in a data file on the analysis system PC and is retrieved by the VAX. The VAX calculates the amount of each dye in the tank based on the volume of bath in the tank (3714 gal.). The VAX, which already has the recipe for the next bath, calculates the amount of makeup dyes needed for the next dyeing. A new formula extension sheet is printed out in the control room which shows the standard recipe, the amount of dye in the holding tank, and the difference, which is the adjusted recipe.

Auxiliary chemicals, which are not depleted during the dyeing process, must also be replenished due to dilution. Since the amount of auxiliary chemicals in the bath does not have to be exact, the makeup amount is estimated based on the amount of dyebath recovered from the previous dyeing. At the time of the reuse trials, it was estimated that $70 \%$ of each bath is recovered, so a $30 \%$ chemical makeup was used. Further calculation now shows that the makeup value should be closer to $40 \%$. However, this discrepancy had no detectable adverse effects on quality of the carpets dyed in the reuse trials, and a $70 \%$ reduction in auxiliary chemicals was successfully demonstrated in each reuse run. 
The use of custom developed software for the analysis system and modifications to the plant's PLC software allow for full automation of the dyebath reuse process. Since the automated dyebath reuse process requires approximately the same amount of operator attention as the standard dyeing process, dyebath reuse can now be successfully implemented without the problems associated with human involvement. 


\section{Appendix D. Absorbance Measurement and Calculation of Dye Concentrations}

Incoming light from the two sides of the dual flow cell passes through identical diffraction gratings. The spectra produced by the gratings fall on CCD detectors which contain 1,024 pixels each. The result is measurement of two different absorption spectra: one for the spent dyebath sample, and one for the reference solution.

As the light source illuminates the array, the voltage levels on the pixels are read one at a time. The sampling frequency of the system is set at $8 \mathrm{kHz}$, because this lets the maximum amount of light shine on the pixels without saturating the array. The voltage readings go through an A/D converter, and the digitized results are treated as raw data. These data are read five times, then averaged for each pixel for both the sample and reference sides. The raw data are then smoothed by averaging the (five-reading average) raw data for each pixel with the raw data value for the four pixels on either side of it. These smoothed values are then stored for each pixel, for both the sample and reference sides.

Calculation of absorbance from the raw data values begins by establishing instrument sensitivity. Raw data values are measured (in advance) under conditions know as DARK and REFERENCE. The DARK values are raw data values obtained at each pixel, for both the sample and reference sides, with the light source turned off. The REFERENCE values are raw data values obtained at each pixel for both the sample and reference sides, with background solution in both sides of the flow cell. (Note that the REFERENCE value is a characterization of the instrument and should not be confused with raw data collected for the reference side of the flow cell while measuring a dye bath.)

Transmission and absorbance values are then calculated for each pixel from the raw data for the sample and the DARK and REFERENCE readings, using the equations:

$$
\begin{aligned}
& \mathrm{T}=\frac{\text { raw data value }- \text { DARK }}{\text { REFERENCE }- \text { DARK }} \\
& \mathrm{A}=-\log (\mathrm{T})
\end{aligned}
$$

If the calculated absorbance value is less than 0 , the absorbance value is set at 0 .

There is an absorbance value for each pixel on both the sample and reference sides of the array. The pixels are mapped to wavelengths using the following equations, as determined through calibration of the detector using a mercury argon calibration lamp with a known spectral output:

Sample: $\quad$ Wavelength $=-7.5$ e-5 [pixel] $^{2}+0.585398$ [pixel] +326.062

Reference: Wavelength $=-5.8$ e-5 [pixel $]^{2}+0.577980[$ pixel $]+329.362$

The absorbance readings for each pixel of the reference side are subtracted from the absorbance for the pixel on the sample side which represents the same wavelength. This subtraction provides the absorbance value at that wavelength for just the dyes. Measuring the absorbance of the background solution simultaneously with each measurement of a sample (as opposed to measuring the background absorbance once and subsequently measuring the samples in the same flow cell) provides assurance that any fluctuations in the output of the light source do not introduce errors in the calculated absorbance of the dyes. This is known as dual beam mode. 
Absorbance spectrophotometry is typically performed using the absorbance values obtained at wavelengths of 410,510 and $610 \mathrm{~nm}$. These wavelengths are used because they are usually near the absorbance peaks of yellow, red, and blue dyes respectively, and have minimal interference from the non-peak dyes. However, the tungsten halogen light source provides limited output at short wavelengths, and the losses over the 400 foot length of the fiber optic cables resulted in inadequate light intensity at the spectrometer at $410 \mathrm{~nm}$. The light output intensity increases rapidly with wavelength, and satisfactory results were obtained at $425 \mathrm{~nm}$. The wavelengths chosen for the experiment were therefore changed to 425,510 and $610 \mathrm{~nm}$. It was noted that the peak absorbance of the yellow dye in Dye System \#2 is actually closer to $425 \mathrm{~nm}$, so this change is quite suitable. The bandwidth was set at $10 \mathrm{~nm}$, centered about these three wavelengths.

According to Beer's law, absorbance at a given wavelength is linearly related to concentration:

$$
A=a b c
$$

where

$$
\begin{aligned}
& a=\text { molar absorbtivity of the dye } \\
& b=\text { path length of the flow cell } \\
& c=\text { concentration of the dye }
\end{aligned}
$$

For measurement of a solution of mixed dyes, as is the case with the spent dyebath, the total absorbance at each wavelength is the sum of the absorbance of each dye component at that wavelength.

In order to calculate concentrations of mixed dyes in solution, a series of calibration curves must first be prepared for each dye. Standard solutions of known concentrations are prepared for a range of concentrations of each dye. The absorbances are measured for each of these solutions at 425 , 510 and $610 \mathrm{~nm}$. Linear regression of the absorbance vs. concentration data provides the slopes (m) and intercepts (b) for each of three dyes at each of three wavelengths, for a total of nine curves. These provide the elements for slope and intercept matrices, and the concentration of each dye in the spent dyebath may be calculated from its measured absorbance values with the matrix equation:

$$
\left[\begin{array}{l}
c_{y} \\
c_{r} \\
c_{b}
\end{array}\right]=\left[\begin{array}{lll}
m_{425, y} & m_{425, r} & m_{425, b} \\
m_{510, y} & m_{510,5} & m_{510, b} \\
m_{610, y} & m_{610, r} & m_{610, b}
\end{array}\right]^{-1}\left\{\left[\begin{array}{l}
A_{425} \\
A_{510} \\
A_{610}
\end{array}\right]-\left[\begin{array}{l}
b_{425} \\
b_{510} \\
b_{610}
\end{array}\right]\right\}
$$

The intercept matrix values (b) are the average of the yellow, red, and blue intercepts at each wavelength.

The results of the calibration for dye solutions made with both nylon 6 and nylon 6,6 background solutions can be found in Appendix E. 


\section{Appendix E. \\ Calibration and Validation of the Analysis System}

The analysis system was calibrated and validated several times for Dye System \#2 with the dyes in both nylon 6 and nylon 6,6 background solutions.

\section{Table 7. Nylon 6,6 Calibration for Non-Automated Dyebath Reuse Trial and Automated Dyebath Reuse Trial, Part I}

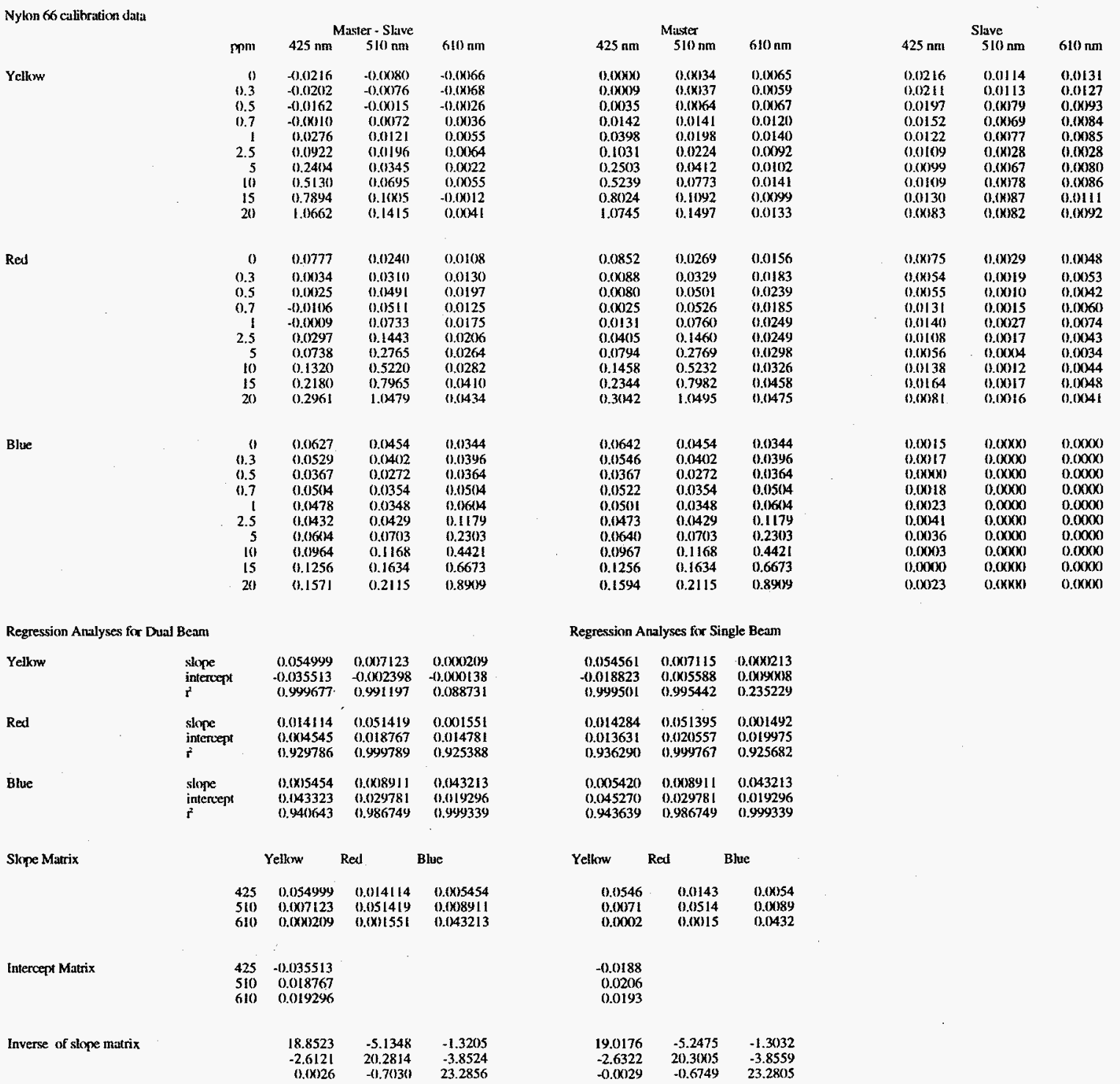


Table 8. Nylon 6 Calibration for Non-Automated Dyebath Reuse Trial and Automated Dyebath Reuse Trial, Part I

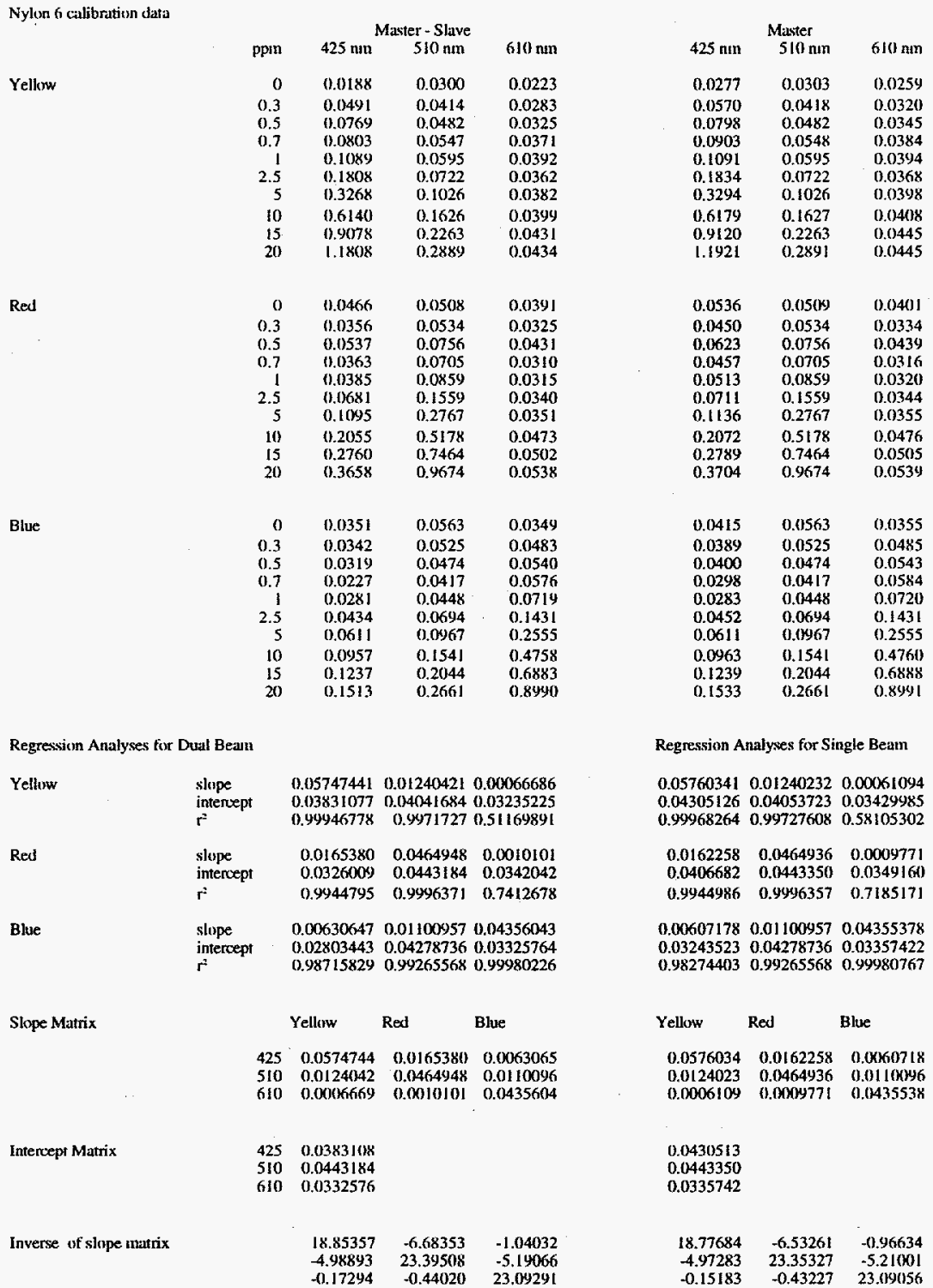


Table 9. Nylon 6 Validation Data for Non-Automated Dyebath Reuse Trial

\begin{tabular}{|c|c|c|c|}
\hline Lab Analysis & \multirow{2}{*}{\multicolumn{3}{|c|}{ Validation Analysis }} \\
\hline Y R B & Yellow & & Blue \\
\hline 1000 & 9.351 & 0 & $\overline{0}$ \\
\hline $\begin{array}{lll}0 & 10 & 0\end{array}$ & 1.240 & 9.280 & 0 \\
\hline $\begin{array}{lll}0 & 0 & 10\end{array}$ & 0.694 & 0 & 9.532 \\
\hline 102020 & 11.771 & 18.628 & 18.160 \\
\hline $20 \quad 10 \quad 20$ & 21.354 & 7.525 & 18.268 \\
\hline
\end{tabular}

Table 10. Nylon 6 Validation Data for Automated Dyebath Reuse Trial, Part I

\begin{tabular}{|c|c|c|c|}
\hline \multirow{3}{*}{$\begin{array}{l}\text { Lab Analysis } \\
\begin{array}{llll}\text { Y R B B } & \\
0.5 & 0.5 & 2.5\end{array}\end{array}$} & \multicolumn{3}{|c|}{ Validation Analysis } \\
\hline & Yellow & Red & Blue \\
\hline & 0.125 & 0.172 & $\overline{2.149}$ \\
\hline $\begin{array}{lll}1.5 & 0.5 & 5\end{array}$ & 0.768 & 0.086 & 4.598 \\
\hline 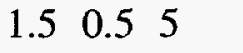 & 1.272 & 0.061 & 4.688 \\
\hline $0.51 .5 \quad 5$ & 0.097 & 1.258 & 4.701 \\
\hline $\begin{array}{lll}0.5 & 1.5 & 5\end{array}$ & 0 & 1.175 & 4.589 \\
\hline $\begin{array}{lll}2.5 & 2.5 & 7.5\end{array}$ & 1.923 & 2.315 & 7.087 \\
\hline $\begin{array}{lll}2.5 & 2.5 & 7.5\end{array}$ & 1.890 & 2.271 & 7.001 \\
\hline $\begin{array}{lll}0 & 0 & 2\end{array}$ & 0 & 0 & 1.836 \\
\hline
\end{tabular}


Table 11. Nylon 6,6 Calibration for Automated Dyebath Reuse Trial, Part II

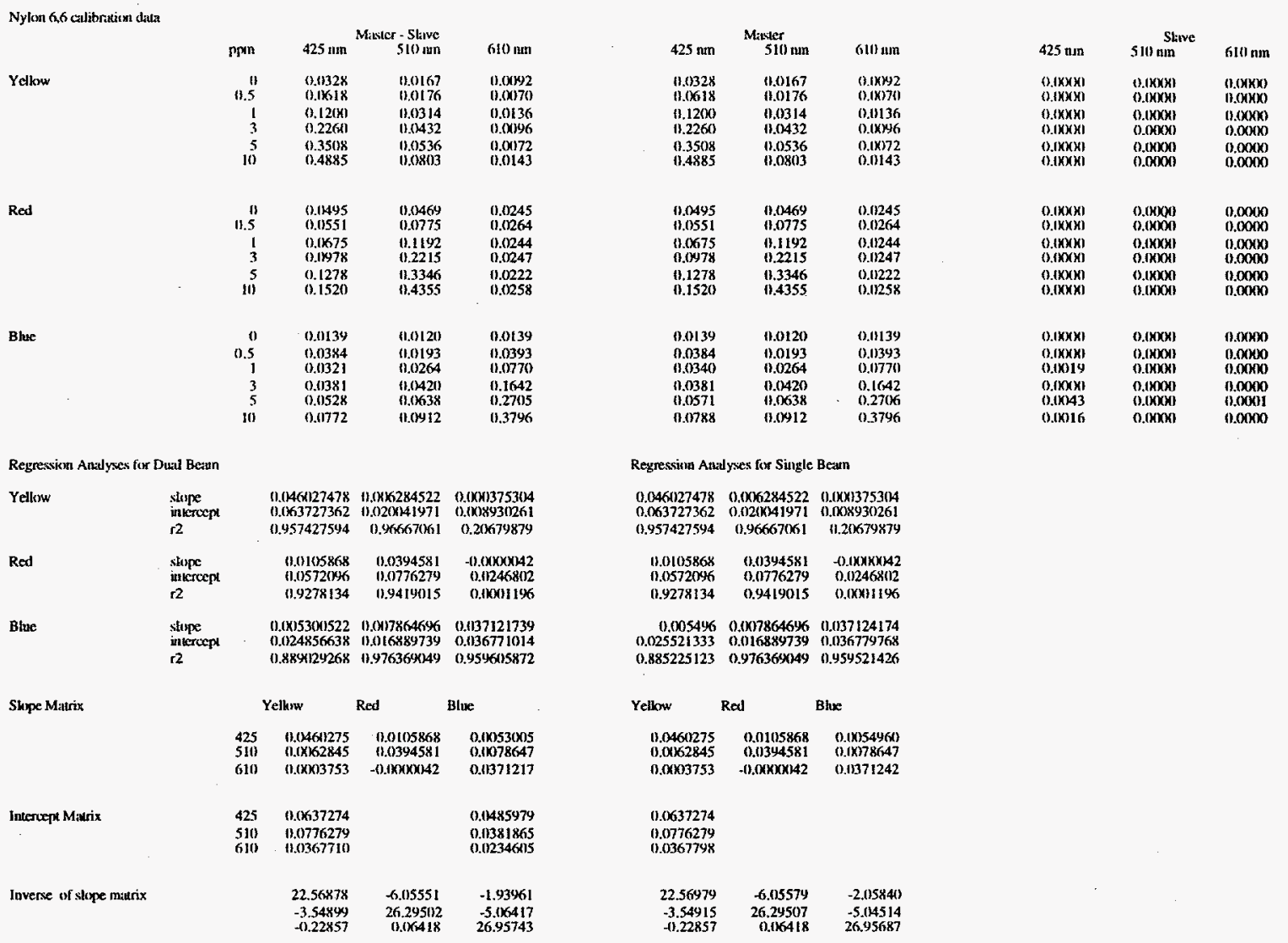


Table 12. Nylon 6 Calibration for Automated Dyebath Reuse Trial, Part II

Nylon 6 calibritukn data

\begin{tabular}{|c|c|}
\hline \multicolumn{2}{|l|}{ Yellorr } \\
\hline \multicolumn{2}{|l|}{ Real } \\
\hline \multicolumn{2}{|l|}{ Blue } \\
\hline \multicolumn{2}{|c|}{ Regressiur Antidyes for Dual Beiun } \\
\hline Yelkiw & $\begin{array}{l}\text { sloppe } \\
\text { intercept } \\
\sqrt{2} 2\end{array}$ \\
\hline Real & $\begin{array}{l}\text { skope } \\
\text { intercept } \\
r_{2}^{2}\end{array}$ \\
\hline Blue & $\begin{array}{l}\text { slope } \\
\text { inpercepn }\end{array}$ \\
\hline
\end{tabular}

$\begin{array}{rl}\text { pprn } & 425 \mathrm{um} \\ 0 & 0.0174 \\ 0.5 & 0.06633 \\ 1 & 0.1140 \\ 3 & 0.2225 \\ 5 & 0.3559 \\ 10 & 0.5039\end{array}$

$\begin{array}{rl}11.5 & 0.0167 \\ 11 & 0.013149 \\ 1 & 0.04 \times 3 \\ 3 & 0.07717 \\ 5 & 0.1115 \\ 10 & 0.1577\end{array}$

\begin{tabular}{|c|c|}
\hline 10.0256 & $\begin{array}{l}1.0173 \\
110.0199\end{array}$ \\
\hline 0.0933 & $\begin{array}{l}\text { 1.10208 } \\
\text { 1.020 }\end{array}$ \\
\hline 0.1842 & $\begin{array}{l}10.048 \\
10.0193\end{array}$ \\
\hline 102880 & 0019193 \\
\hline
\end{tabular}

\begin{tabular}{|c|c|c|c|}
\hline ( & $0.0 \times 45$ & n..(KK) & 0.0183 \\
\hline & 0.0138 & 0.02017 & $\begin{array}{l}10.0462 \\
0.0797\end{array}$ \\
\hline & $\begin{array}{l}0.1214 \\
0.1262\end{array}$ & $\begin{array}{l}1.0289 \\
0.0481\end{array}$ & 0.1662 \\
\hline & 0.0473 & 0.16626 & 11.21187 \\
\hline & 0.0518 & n.ovy3y & 01.4115 \\
\hline
\end{tabular}

Stupe Matrix

$\begin{array}{lll}0.048322087 & 0.167755269 \% & 0.0061218187\end{array}$ $\begin{array}{llll}0.0661597348 & 0.948397856 & 0.079141406\end{array}$

$0.56159734 \times 0.948397856 \quad 0.07914140$ $\begin{array}{lll}0.0138296 & 0.13499520 & 0.06113868 \\ 0.01376872 & 0.13470227 & 0.01871066 \\ 0.0671832 & 0.4706364 & 0.5613435\end{array}$

$0.0042013826 \quad 0.0181866713 \quad 0.037476174$ $0.0114514232 \quad 0.0177665159 \quad 0.01322691(1)$ $0.85658239 \quad 0.96610952 \quad 0.941137896$

$$
\text { Yelkw Red Blue }
$$

$\begin{array}{llll}425 & 0.0483221 & 0.11138246 & 0.00420138 \\ 510 & 0.0075527 & 0.13399520 & 0.0080671\end{array}$ $\begin{array}{llll}5 I 0 & 0.0075527 & 0.0349520 & 0.0080671 \\ 6 I 0 & 0.0612181 & 0.1603868 & 0.0374762\end{array}$

Intercent Mitrix

$$
51
$$

$425 \quad 0.05628666$

$\begin{array}{rr}510 & 0.0470227 \\ \text { filo } & 0.0322691\end{array}$

$0.032826 x]$

0.0295472
0.0238401

\begin{tabular}{|c|c|c|}
\hline & $\begin{array}{l}\text { Master } \\
510 \mathrm{nun}\end{array}$ & $6110 \mathrm{mrn}$ \\
\hline 0.0174 & $\begin{array}{l}0.0145 \\
0.0298\end{array}$ & $\begin{array}{l}0.0159 \\
0.0240\end{array}$ \\
\hline & 0.0344 & 0.0229 \\
\hline & 0.0461 & 00 \\
\hline & 0.0713 & (1).0227 \\
\hline
\end{tabular}

inverse of stipe mantrix

$$
\begin{array}{rrr}
21.880178 & -7.56614 & -1.82575 \\
-4.11931 & -26.50672 & -5.24377 \\
-1.08482 & -0.22954 & 26.74255
\end{array}
$$

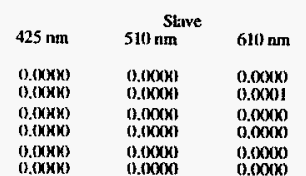

$\begin{array}{lll}0.00169 & 0.0000 & 0.00000 \\ 0.00613 & 0.0000 & 0.0000\end{array}$

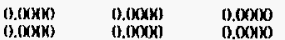

$0.0 \% 910-0.00000 \quad 0.0001$

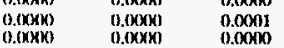

$\begin{array}{lll}0.1115 & 0.2880 & 0.0194 \\ 0.1577 & 0.4210 & 0.0232\end{array}$

$0.0 \% 95 \quad 0.0 \times 91 \quad 0.018$

$\begin{array}{lll}0.0138 & 0.0207 & 0.0462 \\ 0.0214 & 0.0284 & 0.0797\end{array}$

$0.11262 \quad 0.0481 \quad 0.1662$

$\begin{array}{lll}0.1473 & 0.0627 & 13.2087 \\ 0.0521 & 0.0939 & 11.41154\end{array}$

Regression Analyses fir Single Beam

$\begin{array}{llll}0.048322087 & 0.0(K) 75526 \% & 0.000214261\end{array}$

(1)

$\begin{array}{lll}0.0138296 & 0.13349520 & 0.0003861 \\ 0.0276872 & 0.104711227 & 0.0187452\end{array}$ $\begin{array}{lll}0.9671 \times 32 & 0.9706364 & 0.5580163\end{array}$

0.004325913 n.10181649565 0.037485565 0.01432476 1.017673913 0.032255246

Yelkw Red Blue

$0.1483221 \quad 0.0138296 \quad$ 11.0K43259 $0.1075527-0.039952 \pi \quad 0.0 \times 130646$

0.1562866

0.1470227
0.1322552

$\begin{array}{rrr}21.88093 & -7.56552 & -0.89647 \\ -4.11977 & 26.50666 & -5.231469 \\ -0.18264 & -0.22977 & 26.73593\end{array}$ 
Table 13. Nylon 6,6 Validation Data for Automated Dyebath Reuse Trial, Part II

\begin{tabular}{|c|c|c|c|}
\hline \multirow{2}{*}{$\begin{array}{c}\text { Lab Analysis } \\
\text { Y R B }\end{array}$} & \multicolumn{3}{|c|}{ Validation Analysis } \\
\hline & Yellow & Red & Blue \\
\hline 252 & 1.172 & 5.742 & 2.213 \\
\hline & 2.227 & 5.595 & 2.349 \\
\hline & 2.234 & 5.918 & 2.437 \\
\hline Average & 1.878 & 5.752 & 2.333 \\
\hline 505 & 5.708 & 0.000 & 5.677 \\
\hline & 5.671 & 0.000 & 5.585 \\
\hline & 5.591 & 0.000 & 5.525 \\
\hline Average & 5.657 & 0.000 & 5.596 \\
\hline 235 & 1.961 & 3.392 & 5.867 \\
\hline & $\mathrm{xxx}$ & $\mathbf{X X X}$ & $x x x$ \\
\hline & $\mathrm{xxx}$ & $\mathrm{XxX}$ & $\mathrm{xxx}$ \\
\hline Average & 1.961 & 3.392 & 5.867 \\
\hline \multirow[t]{3}{*}{222} & 1.850 & 2.038 & 2.645 \\
\hline & 1.872 & 1.968 & 2.569 \\
\hline & 1.835 & 1.960 & 2.506 \\
\hline Average & 1.852 & 1.989 & 2.573 \\
\hline
\end{tabular}


Table 14. Nylon 6 Validation Data for Automated Dyebath Reuse Trial, Part II

\begin{tabular}{|c|c|c|c|}
\hline \multirow{2}{*}{$\begin{array}{c}\text { Lab Analysis } \\
\text { Y R B }\end{array}$} & \multicolumn{3}{|c|}{ Validation Analysis } \\
\hline & Yellow & Red & Blue \\
\hline & 1.444 & 3.133 & 5.46 \\
\hline \multirow{2}{*}{235} & 1.717 & 3.222 & 5.554 \\
\hline & 1.857 & 3.223 & 5.619 \\
\hline Average & 1.673 & 3.193 & 5.544 \\
\hline \multirow[t]{3}{*}{222} & 1.837 & 2.09 & 2.489 \\
\hline & 2.149 & 2.218 & 2.602 \\
\hline & 2.044 & 2.301 & 2.651 \\
\hline Average & $2 . \overline{010}$ & 2.203 & 2.581 \\
\hline \multirow{3}{*}{505} & 5.517 & 0.026 & 5.833 \\
\hline & 5.815 & 0.173 & 6.05 \\
\hline & 5.724 & 0.324 & 6.14 \\
\hline Average & 5.685 & 0.174 & 6.008 \\
\hline \multirow[t]{3}{*}{252} & 2.461 & 5.522 & 2.505 \\
\hline & 2.687 & 5.643 & 2.698 \\
\hline & 2.794 & 5.686 & 2.788 \\
\hline Average & 2.647 & 5.617 & 2.664 \\
\hline \multirow[t]{3}{*}{003} & 0 & 0 & 3.271 \\
\hline & 0 & 0 & 3.472 \\
\hline & 0 & 0.07 & 3.557 \\
\hline Average & 0.000 & 0.023 & 3.433 \\
\hline \multirow{3}{*}{1000} & 10.803 & 0 & 0 \\
\hline & 11.155 & 0 & 0.074 \\
\hline & 11.296 & 0 & 0.164 \\
\hline Average & 11.085 & 0.000 & 0.079 \\
\hline \multirow{3}{*}{000} & 0 & 0 & 0 \\
\hline & 0 & 0 & 0 \\
\hline & 0 & 0 & 0 \\
\hline Average & 0.000 & 0.000 & 0.000 \\
\hline
\end{tabular}




\section{Appendix F. Dyeing Results in Dyebath Reuse Trials}

Table 15. Carpets Used in Non-Automated Reuse Trial

\begin{tabular}{|l|l|l|l|}
\hline Run & Style & Shade & Fiber \\
\hline 1st & 51455 Alydar & 57403 Blue Chiffon & $\begin{array}{l}\text { Nylon 6,6 Suessen } \\
\text { set }\end{array}$ \\
Reuse & 51455 Alydar & 57405 Royal Sapphire & $\begin{array}{l}\text { Nylon 6,6 Suessen } \\
\text { set }\end{array}$ \\
\hline
\end{tabular}

Table 16. Carpets Used in Automated Dyebath Reuse Trial, Part I

\begin{tabular}{|l|l|l|l|l|l|}
\hline $\begin{array}{l}\text { Reuse } \\
\text { Series }\end{array}$ & Run & Style & Shade & Fiber & Result \\
\hline $\mathbf{1}$ & $\mathbf{1}$ & $\begin{array}{l}\text { MO346 } \\
\text { Centurion }\end{array}$ & $\begin{array}{l}00401 \\
\text { Blue }\end{array}$ & $\begin{array}{l}\text { Nylon 6 } \\
\text { Suessen Set }\end{array}$ & First quality \\
\cline { 2 - 6 } & $\mathbf{2}$ & $\begin{array}{l}\text { MO912 } \\
\text { Cavatina }\end{array}$ & $\begin{array}{l}00401 \\
\text { Blue }\end{array}$ & $\begin{array}{l}\text { Nylon 6 } \\
\text { Suessen Set }\end{array}$ & First quality \\
\cline { 2 - 6 } & $\mathbf{3}$ & $\begin{array}{l}51332 \\
\text { Seattle Slew }\end{array}$ & $\begin{array}{l}34400 \\
\text { Heirloom Blue }\end{array}$ & $\begin{array}{l}\text { Nylon 6,6 } \\
\text { Suessen Set }\end{array}$ & $\begin{array}{l}\text { First quality, } \\
\text { required 2 adds }\end{array}$ \\
\cline { 2 - 6 } & $\mathbf{4}$ & $\begin{array}{l}\text { MO346 } \\
\text { Centurion }\end{array}$ & $\begin{array}{l}00402 \\
\text { Blue }\end{array}$ & $\begin{array}{l}\text { Nylon 6 } \\
\text { Suessen Set }\end{array}$ & $\begin{array}{l}\text { Downgraded } \\
\text { and redyed }\end{array}$ \\
\hline $\mathbf{2}$ & $\mathbf{1}$ & $\begin{array}{l}\text { MO960 } \\
\text { Patterned Perfection }\end{array}$ & $\begin{array}{l}00103 \\
\text { Beige }\end{array}$ & $\begin{array}{l}\text { Nylon 6,6 } \\
\text { Suessen Set }\end{array}$ & $\begin{array}{l}\text { First quality, } \\
\text { required 1 add }\end{array}$ \\
\cline { 2 - 6 } & $\mathbf{2}$ & $\begin{array}{l}\text { MO960 } \\
\text { Patterned Perfection }\end{array}$ & $\begin{array}{l}00700 \\
\text { Brown }\end{array}$ & $\begin{array}{l}\text { Nylon 6,6 } \\
\text { Suessen Set }\end{array}$ & $\begin{array}{l}\text { First quality, } \\
\text { required 1 add }\end{array}$ \\
\cline { 2 - 6 } & $\mathbf{3}$ & $\begin{array}{l}\text { M1110 } \\
\text { MCW Saxony 2 12 }\end{array}$ & $\begin{array}{l}00212 \\
\text { Gold }\end{array}$ & $\begin{array}{l}\text { Nylon 6,6 } \\
\text { Suessen Set }\end{array}$ & First quality \\
\cline { 2 - 6 } & $\mathbf{4}$ & $\begin{array}{l}\text { M1110 } \\
\text { MCW Saxony 2 12 }\end{array}$ & $\begin{array}{l}00212 \\
\text { Gold }\end{array}$ & $\begin{array}{l}\text { Nylon 6,6 } \\
\text { Suessen Set }\end{array}$ & First quality \\
\cline { 2 - 6 } & $\mathbf{0 0 3 3 2}$ \\
\cline { 2 - 6 } & Gro68 & $\begin{array}{l}\text { Nylon 6,6 } \\
\text { Suessen Set }\end{array}$ & $\begin{array}{l}\text { First quality, } \\
\text { required 1 add }\end{array}$ \\
\hline
\end{tabular}

Table 17. Range of Dyes Used in Automated Dyebath Reuse Trial, Part I

\begin{tabular}{|l|l|l|l|}
\hline Reuse Series & Dye & $\begin{array}{l}\text { Minimum } \\
\text { Amount (g) }\end{array}$ & $\begin{array}{l}\text { Maximum } \\
\text { Amount (g) }\end{array}$ \\
\hline $\mathbf{1}$ & Yellow & 47 & \\
\hline & Red & 40 & 101 \\
& Blue & 222 & 715 \\
\hline $\mathbf{2}$ & Yellow & 83 & 286 \\
& Red & 19 & 84 \\
& Blue & 36 & 687 \\
\hline
\end{tabular}


Table 18. Analysis Results and Savings for Automated Dyebath Reuse Trial, Part I

\begin{tabular}{|c|c|c|c|c|c|c|}
\hline \begin{tabular}{|l} 
Reuse \\
Series
\end{tabular} & Run & $\begin{array}{l}\text { Analysis } \\
\text { Results } \\
\text { (ppm) }\end{array}$ & $\begin{array}{c}\text { Recovered } \\
\text { Dye } \\
\text { Quantity } \\
\text { (grams) }\end{array}$ & $\begin{array}{c}\text { Process } \\
\text { Start } \\
\text { Temp } \\
\text { (F) }\end{array}$ & $\begin{array}{l}\text { Energy } \\
\text { Savings* } \\
\text { (MBTU) }\end{array}$ & $\begin{array}{c}\text { Auxiliary } \\
\text { Chemical } \\
\text { Savings } \\
(1 \mathrm{bm})\end{array}$ \\
\hline \multirow[t]{4}{*}{$\mathbf{1}$} & 1 & & & Standard & & \\
\hline & 2 & $\begin{array}{lr}\text { Yellow } & 0 \\
\text { Red } & 0 \\
\text { Blue } & 3.334\end{array}$ & 44 & 142 & 2.53 & 45.0 \\
\hline & 3 & $\begin{array}{lr}\text { Yellow } & 0 \\
\text { Red } & 0 \\
\text { Blue } & 7.551\end{array}$ & 99 & 135 & 2.31 & 60.9 \\
\hline & 4 & $\begin{array}{lr}\text { Yellow } & 0 \\
\text { Red } & 0 \\
\text { Blue } & 0.354\end{array}$ & 5 & 127 & 2.07 & 47.5 \\
\hline \multirow[t]{5}{*}{2} & 1 & & & Standard & & \\
\hline & 2 & $\begin{array}{lr}\text { Yellow } & 0.016 \\
\text { Red } & 0 \\
\text { Blue } & 0\end{array}$ & 0.2 & 137 & 2.38 & 41.8 \\
\hline & 3 & $\begin{array}{lr}\text { Yellow } & 0.016 \\
\text { Red } & 0 \\
\text { Blue } & 0\end{array}$ & 0.2 & 129 & 2.13 & 46.2 \\
\hline & 4 & $\begin{array}{lr}\text { Yellow } & 0.016 \\
\text { Red } & 0 \\
\text { Blue } & 0\end{array}$ & 0.2 & 135 & 2.32 & 46.8 \\
\hline & 5 & $\begin{array}{lr}\text { Yellow } & 0.016 \\
\text { Red } & 0 \\
\text { Blue } & 0\end{array}$ & 0.2 & 129 & 2.13 & 49.2 \\
\hline
\end{tabular}

* Energy savings are calculated based on an assumed year-round average starting temperature of $60 \mathrm{~F}$ for the standard process.

Table 19. Carpets Used in Automated Dyebath Reuse Trial, Part II

\begin{tabular}{|c|c|c|c|c|}
\hline$\overline{\text { Run }}$ & Style & Shade & Fiber & Result \\
\hline 1 & $\begin{array}{l}51334 \\
\text { Affirmed }\end{array}$ & $\begin{array}{l}34402 \\
\text { Royal Blue }\end{array}$ & $\begin{array}{l}\text { Nylon 6,6 } \\
\text { Suessen Set }\end{array}$ & $\begin{array}{l}\text { First quality, } \\
\text { required } 1 \text { add }\end{array}$ \\
\hline 2 & \begin{tabular}{|l} 
M0786 \\
Voracious
\end{tabular} & $\begin{array}{l}00403 \\
\text { Blue }\end{array}$ & $\begin{array}{l}\text { Nylon 6,6 } \\
\text { Suessen Set }\end{array}$ & $\begin{array}{l}\text { First quality, } \\
\text { required } 1 \text { add }\end{array}$ \\
\hline 3 & $\begin{array}{l}\text { M0786 } \\
\text { Voracious }\end{array}$ & $\begin{array}{l}00402 \\
\text { Blue }\end{array}$ & $\begin{array}{l}\text { Nylon 6,6 } \\
\text { Suessen Set }\end{array}$ & First quality \\
\hline 4 & $\begin{array}{l}\text { M0113 } \\
\text { Graceful Imprs }\end{array}$ & $\begin{array}{l}00504 \\
\text { Gray }\end{array}$ & $\begin{array}{l}\text { Nylon 6,6 } \\
\text { Suessen Set }\end{array}$ & $\begin{array}{l}\text { First quality, } \\
\text { required } 1 \text { add }\end{array}$ \\
\hline 5 & $\begin{array}{l}51332 \\
\text { Seattle Slew }\end{array}$ & $\begin{array}{l}04532 \\
\text { Aged Pewter }\end{array}$ & $\begin{array}{l}\text { Nylon } 6,6 \\
\text { Suessen Set }\end{array}$ & $\begin{array}{l}\text { Required } 3 \text { adds, } \\
\text { then downgraded and redyed }\end{array}$ \\
\hline
\end{tabular}


Table 20. Range of Dyes Used in Automated Dyebath Reuse Trial, Part II

\begin{tabular}{|l|l|l|}
\hline Dye & Minimum Amount (g) & Maximum Amount (g) \\
\hline Yellow & 36 & 872 \\
Red & 154 & 527 \\
Blue & 305 & 868 \\
\hline
\end{tabular}

Table 21. Analysis Results and Savings for Automated Dyebath Reuse Trial, Part II

\begin{tabular}{|c|c|c|c|c|c|}
\hline Run & $\begin{array}{c}\text { Analysis Results } \\
\text { (ppm) }\end{array}$ & $\begin{array}{c}\text { Recover } \\
\text { ed Dye } \\
\text { Quantity } \\
\\
\text { (grams) }\end{array}$ & $\begin{array}{c}\text { Process } \\
\text { Start } \\
\text { Temp } \\
\\
\text { (F) }\end{array}$ & $\begin{array}{c}\text { Energy } \\
\text { Savings* } \\
\text { (MBTU) }\end{array}$ & $\begin{array}{c}\text { Auxiliary } \\
\text { Chemical } \\
\text { Savings } \\
\text { (lbm) }\end{array}$ \\
\hline 1 & & & Standard & & \\
\hline 2 & $\begin{array}{lr}\text { Yellow } & 0 \\
\text { Red } & 0 \\
\text { Blue } & 0.364 \\
\end{array}$ & 5 & 142 & 2.53 & $\overline{77.2}$ \\
\hline 3 & $\begin{array}{lr}\text { Yellow } & 0 \\
\text { Red } & 2.671 \\
\text { Blue } & 6.446 \\
\end{array}$ & $\begin{array}{l}35 \\
85 \\
\end{array}$ & 139 & 2.44 & 43.2 \\
\hline 4 & $\begin{array}{lr}\text { Yellow } & 3.160 \\
\text { Red } & 5.095 \\
\text { Blue } & 12.700 \\
\end{array}$ & $\begin{array}{r}42 \\
68 \\
168 \\
\end{array}$ & 144 & 2.59 & 76.5 \\
\hline 5 & $\begin{array}{lr}\text { Yellow } & 5.121 \\
\text { Red } & 5.256 \\
\text { Blue } & 16.236 \\
\end{array}$ & $\begin{array}{r}68 \\
70 \\
215 \\
\end{array}$ & 132 & 2.22 & 62.4 \\
\hline
\end{tabular}

* Energy savings are calculated based on an assumed year-round average starting temperature of $60 \mathrm{~F}$ for the standard process. 
Appendix G.

Demonstrated Energy, Environmental, and Economic Saving

Table 22. Calculation of Demonstrated Energy Savings

\begin{tabular}{|c|c|c|}
\hline Reuse Trial Part & Series/Carpet & Startup Temperature (F) \\
\hline I & $1 / 2$ & 142 \\
& $1 / 3$ & 135 \\
& $1 / 4$ & 127 \\
& $2 / 2$ & 137 \\
& $2 / 3$ & 129 \\
& $2 / 4$ & 135 \\
II & $2 / 5$ & 129 \\
& $1 / 2$ & 142 \\
& $1 / 3$ & 139 \\
& $1 / 4$ & 144 \\
Average Reuse Temperature & 132 \\
Reuse Volume per Batch & $136 \mathrm{~F}$ \\
Year-Round Startup Temperature & 3,700 gal \\
without Reuse & $60 \mathrm{~F}$ \\
\hline
\end{tabular}

$$
\begin{aligned}
\underset{\text { per Batch }}{\text { Energy Savings }} & =(136 \mathrm{~F}-60 \mathrm{~F}) \bullet \frac{3,700 \mathrm{gal}}{\text { batch }} \bullet \frac{8.34 \mathrm{lbm}}{\text { gallon }} \bullet \frac{1 \mathrm{BTU}}{\mathrm{lbm} \cdot \mathrm{F}} \\
& =2.35 \text { million BTU per reuse batch }
\end{aligned}
$$


Table 23. Calculation of Demonstrated Reduction in Pollutants Released

\begin{tabular}{|c|c|c|c|c|}
\hline & $\begin{array}{l}\text { COD } \\
\mathrm{mg} / \mathrm{L}\end{array}$ & $\begin{array}{l}\text { Water/Bath } \\
\text { gallons }\end{array}$ & $\begin{array}{l}\text { Quantity } \\
\text { pounds }\end{array}$ & $\begin{array}{c}\text { COD } \\
\text { pounds }\end{array}$ \\
\hline \multicolumn{5}{|c|}{ Standard Production } \\
\hline Run 1 (Beck 52) & 3,000 & 5,955 & 49,665 & 149.0 \\
\hline Run 2 (Beck 63) & 1,700 & 5,955 & 49,665 & 84.4 \\
\hline Run 3 (Beck 54) & 1,800 & 5,955 & 49,665 & 89.4 \\
\hline Run 4 (Beck 61) & 2,400 & 5,955 & 49,665 & 119.2 \\
\hline Run 5 (Beck 65) & 1,400 & 5,955 & 49,665 & 69.5 \\
\hline Average & 2,060 & & & 102.3 \\
\hline \multicolumn{5}{|l|}{ Reuse Prerinses } \\
\hline Run 1, Carpet 1 & 1,500 & 2,907 & 24,244 & 36.4 \\
\hline Run 1, Carpet 2 & 1,600 & 2,907 & 24,244 & 38.8 \\
\hline Run 1, Carpet 3 & 2,000 & 2,907 & 24,244 & 48.5 \\
\hline Run 2, Carpet 2 & 1,300 & 2,907 & 24,244 & 31.5 \\
\hline Run 2, Carpet 3 & 1,400 & 2,907 & 24,244 & 33.9 \\
\hline Run 2, Carpet 4 & 2,000 & 2,907 & 24,244 & 48.5 \\
\hline \multirow{2}{*}{$\begin{array}{l}\text { Run 2, Carpet } 5 \\
\text { Average }\end{array}$} & 1,800 & \multirow{2}{*}{2,907} & \multirow{2}{*}{24,244} & 43.6 \\
\hline & 1,657 & & & 40.2 \\
\hline
\end{tabular}

\section{Reuse Dyebaths}

\begin{tabular}{|c|c|c|c|c|}
\hline Run 1, Carpet 1 & 1,300 & 5,955 & 49,665 & 64.6 \\
\hline Run 1, Carpet 2 & 2,200 & 5,955 & 49,665 & 109.3 \\
\hline Run 1, Carpet 3 & 2,000 & 5,955 & 49,665 & 99.3 \\
\hline Run 2, Carpet 2 & 2,100 & 5,955 & 49,665 & 104.3 \\
\hline Run 2, Carpet 3 & 2,000 & 5,955 & 49,665 & 99.3 \\
\hline Run 2, Carpet 4 & 2,500 & 5,955 & 49,665 & 124.2 \\
\hline $\begin{array}{c}\text { Run 2, Carpet } 5 \\
\text { Average }\end{array}$ & $\frac{2,600}{2,100}$ & 5,955 & 49,665 & $\frac{129.1}{104.3}$ \\
\hline
\end{tabular}

Discharge fraction of dyebaths with reuse $=\frac{5,955 \mathrm{gal}-3,700 \mathrm{gal}}{5,955 \mathrm{gal}}=0.379$

Discharge per batch with dyebath reuse $=40.2 \mathrm{lbm}+0.379 \bullet 104.3 \mathrm{lbm}=79.7 \mathrm{lbm}$ COD Pollution reduction $=102.3-79.7=22.6$ pounds $\mathrm{COD}$ per reuse batch 


\section{Table 24. Calculation of Demonstrated Cost Reductions}

Auxiliary Chemical

Defoamer

Antichlor agent

Water softener

Chelating agent

Leveling agent

Lubricant

pH buffer

pH control

pH control

Dye retardant
Unit Cost per pound

0.839

$\$ \quad 0.410$

$\$ \quad 0.377$

$\$ \quad 0.384$

$\$ 0.796$

$\$ 0.505$

$\$ \quad 0.316$

$\$ 0.106$

$\$ 0.108$

$\$ \quad 1.227$
Nylon 6 Recipe Nylon 66 Recipe $\%$ of carpet wt.\% of carpet wt.

Cents per Pound Cents per Pound for Nylon 6 for Nylon 66

Dyes$$
\text { Avg. Residual Average Savings }
$$

$\begin{array}{rr}0.5 & 0.5 \\ 0.13 & 0.17 \\ 0.75 & 0.9 \\ 1.25 & 1.6 \\ 1 & 0.96 \\ & 1.29\end{array}$

0.420

0.070

0.362

0.618

0.764

0.651

0.316

0.5

0.3

0.212

0.054

0.368

Total

2.666

Savings@70\%

1.866

2.241

Yellow dye Red dye

Blue dye

$$
\begin{array}{cr}
\text { Unit } & \text { Cost } \\
\text { per } & \text { pound } \\
\$ & 25.53 \\
\$ & 19.56 \\
\$ & 15.04
\end{array}
$$

(grams/batch) per batch

$\begin{array}{rll}10.07 & \$ & 0.566 \\ 1.56 & \$ & 0.067 \\ 56.5 & \$ & 1.872 \\ \text { Total } & \$ & 2.505\end{array}$

Average Carpet Weight

\begin{tabular}{|c|c|c|c|}
\hline \multicolumn{2}{|c|}{$\begin{array}{l}\text { Cost per } \\
\text { MBTU }\end{array}$} & $\begin{array}{l}\text { Avg. Savings } \\
\text { MBTU/Batch }\end{array}$ & $\begin{array}{l}\text { Average Savings } \\
\text { per batch }\end{array}$ \\
\hline$\$$ & 4.00 & 2.35 & 9.40 \\
\hline Cer & vec & $\begin{array}{l}\text { ge Carpet Weight } \\
\text { pound of Carpet }\end{array}$ & 0.603 \\
\hline
\end{tabular}

1560

Cents Saved per pound of Carpet

0.161

Cost per Savings Average Dollar Savings $1000 \mathrm{gal} \quad 1000 / \mathrm{gal}$ per batch per batch

Water/Sewer$$
\$ 0.9
$$

4.7

4.28

Average Carpet Weight

1560

Cents Saved per pound of Carpet

Total Savings

Auxiliary Chemicals

Cents per pound of Carpet

Dyes

Energy Nylon $6 \quad$ Nylon 66

\begin{tabular}{rr}
\hline Nylon 6 & Nylon 66 \\
1.866 & 2.241 \\
0.161 & 0.161 \\
0.603 & 0.603 \\
0.274 & 0.274 \\
\hline 2.903 & 3.278
\end{tabular}

